\title{
Article \\ Functional and Molecular Properties of DYT-SGCE Myoclonus-Dystonia Patient-Derived Striatal Medium Spiny Neurons
}

\author{
Anna Kutschenko ${ }^{1,+}$, Selma Staege ${ }^{1,2,+}$, Karen Grütz ${ }^{3}{ }^{\mathbb{D}}$, Hannes Glaß ${ }^{4}$, Norman Kalmbach ${ }^{1}$, \\ Thomas Gschwendtberger ${ }^{1,2}$, Lisa M. Henkel ${ }^{1,2}$, Johanne Heine ${ }^{1}$, Anne Grünewald ${ }^{3}{ }^{(D)}$, \\ Andreas Hermann ${ }^{4,5,6} \mathbb{D}_{\text {, Philip Seibler }}{ }^{3}$ and Florian Wegner 1,2,*
}

\section{check for} updates

Citation: Kutschenko, A.; Staege, S.; Grütz, K.; Glaß, H.; Kalmbach, N.; Gschwendtberger, T.; Henkel, L.M.; Heine, J.; Grünewald, A.;

Hermann, A.; et al. Functional and Molecular Properties of DYT-SGCE Myoclonus-Dystonia Patient-Derived Striatal Medium Spiny Neurons. Int. J. Mol. Sci. 2021, 22, 3565. https:// doi.org/10.3390/ijms22073565

Academic Editor: Rivka Ofir

Received: 19 February 2021

Accepted: 24 March 2021

Published: 30 March 2021

Publisher's Note: MDPI stays neutral with regard to jurisdictional claims in published maps and institutional affiliations.

Copyright: (C) 2021 by the authors. Licensee MDPI, Basel, Switzerland. This article is an open access article distributed under the terms and conditions of the Creative Commons Attribution (CC BY) license (https:// creativecommons.org/licenses/by/ $4.0 /)$.
1 Department of Neurology, Hannover Medical School, Carl-Neuberg-Str. 1, 30625 Hannover, Germany; kutschenko.anna@mh-hannover.de (A.K.); staege.selma@mh-hannover.de (S.S.); norman.kalmbach@googlemail.com (N.K.); gschwendtberger.thomas@mh-hannover.de (T.G.); henkel.lisa@mh-hannover.de (L.M.H.); heine.johanne@mh-hannover.de (J.H.)

2 Center for Systems Neuroscience, Bünteweg 2, 30559 Hannover, Germany

3 Institute of Neurogenetics, University of Lübeck, Ratzeburger Allee 160, 23538 Lübeck, Germany; karen.gruetz@neuro.uni-luebeck.de (K.G.); anne.gruenewald@neuro.uni-luebeck.de (A.G.); philip.seibler@neuro.uni-luebeck.de (P.S.)

4 Translational Neurodegeneration Section "Albrecht-Kossel", Department of Neurology, University Medical Center, University of Rostock, Gehlsheimer Str. 20, 18147 Rostock, Germany; hannes.glass@med.uni-rostock.de (H.G.); andreas.hermann@med.uni-rostock.de (A.H.)

5 German Center for Neurodegenerative Diseases Rostock/Greifswald, 18147 Rostock, Germany

6 Center for Transdisciplinary Neurosciences Rostock (CTNR), University Medical Center, University of Rostock, 18147 Rostock, Germany

* Correspondence: wegner.florian@mh-hannover.de; Tel.: +49-511-5323110

$\dagger$ These authors contributed equally to this work.

Abstract: Myoclonus-dystonia (DYT-SGCE, formerly DYT11) is characterized by alcohol-sensitive, myoclonic-like appearance of fast dystonic movements. It is caused by mutations in the SGCE gene encoding $\varepsilon$-sarcoglycan leading to a dysfunction of this transmembrane protein, alterations in the cerebello-thalamic pathway and impaired striatal plasticity. To elucidate underlying pathogenic mechanisms, we investigated induced pluripotent stem cell (iPSC)-derived striatal medium spiny neurons (MSNs) from two myoclonus-dystonia patients carrying a heterozygous mutation in the SGCE gene (c.298T $>$ G and c.304C > T with protein changes W100G and R102X) in comparison to two matched healthy control lines. Calcium imaging showed significantly elevated basal intracellular $\mathrm{Ca}^{2+}$ content and lower frequency of spontaneous $\mathrm{Ca}^{2+}$ signals in SGCE MSNs. Blocking of voltagegated $\mathrm{Ca}^{2+}$ channels by verapamil was less efficient in suppressing $\mathrm{KCl}$-induced $\mathrm{Ca}^{2+}$ peaks of SGCE MSNs. $\mathrm{Ca}^{2+}$ amplitudes upon glycine and acetylcholine applications were increased in SGCE MSNs, but not after GABA or glutamate applications. Expression of voltage-gated $\mathrm{Ca}^{2+}$ channels and most ionotropic receptor subunits was not altered. SGCE MSNs showed significantly reduced GABAergic synaptic density. Whole-cell patch-clamp recordings displayed elevated amplitudes of miniature postsynaptic currents and action potentials in SGCE MSNs. Our data contribute to a better understanding of the pathophysiology and the development of novel therapeutic strategies for myoclonus-dystonia.

Keywords: DYT-SGCE; myoclonus-dystonia; induced pluripotent stem cells; striatal medium spiny neurons; calcium dynamics; patch-clamp electrophysiology; GABAergic synaptic density

\section{Introduction}

Myoclonus-dystonia (DYT-SGCE, previously referred to as DYT11) with onset in childhood or adolescence is characterized by a combination of myoclonic jerks and dystonic symptoms [1-4]. These myoclonic jerks are usually alcohol-responsive and often 
present in the upper body in addition with no or mild to moderate dystonia [5]. Dystonic symptoms of DYT-SGCE mostly present as focal or segmental dystonia manifesting in spasmodic torticollis or writer's cramp $[1,2,6]$. Psychiatric comorbidities frequently accompany motor manifestations in DYT-SGCE including alcohol abuse, anxiety-related and obsessive-compulsive disorders [7-10].

This movement disorder can only be treated symptomatically with systemic pharmacological therapy, e.g., anticholinergic or GABAergic drugs, intramuscular botulinum toxin injection, or deep brain stimulation [11-13]. Thus, a better understanding of the pathophysiology is crucial in order to develop disease-modifying treatment options.

DYT-SGCE myoclonus-dystonia is caused by mutations in the $\varepsilon$-sarcoglycan gene (SGCE) [14]. It is located on chromosome 7q21 and more than 41 different mutations in SGCE are known including exon rearrangements, base pair substitutions, deletions or insertions $[15,16]$. DYT-SGCE is inherited in an autosomal dominant manner with a variable expression and reduced penetrance due to maternal genomic imprinting of the SGCE gene [14,17-19].

The protein $\varepsilon$-sarcoglycan is a member of the sarcoglycan family of transmembrane glycoproteins with six different isoforms $(\alpha-, \beta-, \gamma-, \delta-, \varepsilon-$, and $\zeta$-sarcoglycan). These transmembrane proteins are part of the dystrophin-glycoprotein-complex, which is important for the linkage of the cytoskeleton with the extracellular matrix [20]. A brain specific isoform of SGCE is broadly expressed in different brain regions, predominantly in the cerebral cortex, the cerebellum and the hippocampus $[14,21,22]$, whereas in the striatum a moderate expression of SGCE was found [21].

It was hypothesized that DYT-SGCE dystonia is rather not caused by changes at the neurotransmitter level, but results from alterations in neuronal structures [14,21]. A recent review speculated that loss of $\varepsilon$-sarcoglycan induces neuronal membrane damage leading to calcium accumulation [23]. Calcium homeostasis plays an important role in the regulation of the dopamine D2-receptor [24]. In a ${ }^{123}$ I-IBZM-SPECT (single photon emission computed tomography (SPECT) with the ligand $\left[{ }^{123} \mathrm{I}\right]$ iodobenzamide (IBZM)) study of $S G C E$ mutation carriers, a decreased dopamine D2-receptor availability in the striatum could be detected [25]. Reduced striatal D2-receptors were also found in SGCE knock-out mice showing myoclonus, impaired motor skills, hyperactivity, anxiety and depression [26]. In addition, these mice exhibited an altered monoamine metabolism with significantly increased striatal dopamine levels and its metabolites as well as inversely decreased serotonin levels [27]. GABAergic networks may also play a crucial pathophysiological role in DYT-SGCE because patients reported improvement of motor symptoms following alcohol administration $[7,28,29]$. Moreover, studies have demonstrated that the dystrophinglycoprotein-complex co-localizes with GABAergic synapses and that disturbances of the dystrophin-glycoprotein-complex result in a reduced postsynaptic clustering of $\mathrm{GABA}_{\mathrm{A}}$ receptors [30-32].

In a genetic mouse model of SGCE deficiency, impaired striatal plasticity was found despite the absence of an obvious motor phenotype [33]. Abnormal nuclear envelopes could be detected in striatal medium spiny neurons in SGCE knock-out mice. However, data on striatum-specific $S G C E$ conditional knock-out mice suggested that a loss of $\varepsilon$-sarcoglycan in the striatum only contributed to motor deficits while a loss of $\varepsilon$-sarcoglycan in other brain regions might lead to myoclonus and abnormal nuclear envelopes [34]. In accordance with this assumption, it could be shown that the knockdown of SGCE in the cerebellum produced motor symptoms with cerebellar involvement in a mouse model of DYT-SGCE [35]. A neuroimaging study in DYT-SGCE patients detected white matter changes in the brain stem suggesting an abnormal function of networks including cerebellum, brain stem and basal ganglia [36]. Taken together, dysfunction of the cerebello-thalamo-cortical and/or striato-pallido-thalamo-cortical pathways was suggested supporting the classification of DYT-SGCE as a neurodevelopmental circuit disorder [23]. 
In this study, we investigated the molecular and functional phenotype of striatal medium spiny neurons (MSNs) differentiated from DYT-SGCE patient-derived induced pluripotent stem cells (iPSCs) and from healthy controls by adapting two of our previously established protocols $[37,38]$. To evaluate the functional phenotype of disease-specific and control MSNs, we used calcium imaging and whole-cell patch-clamp recordings. Furthermore, gene expression analysis of voltage-gated $\mathrm{Ca}^{2+}$ channel subunits and ionotropic receptor subunits as well as morphometric analysis of MSNs including GABAergic synaptic density were performed to identify novel treatment targets for DYT-SGCE dystonia.

\section{Results}

\subsection{Differentiation of iPSCs into Medium Spiny Neurons (MSNs)}

For modeling myoclonus-dystonia in vitro, we differentiated MSNs for 70 days from iPSC origin (Figure 1). After plating embryoid bodies (EBs), neural progenitor cells expressed nestin around day 18 during maturation (data not shown). The quantitative immunocytochemical analysis of mature MSNs revealed 81-85\% $\beta$-tubulin III (TUJ1)positive neurons of which $63-73 \%$ were positive for the neurotransmitter $\gamma$-aminobutyric acid (GABA). Approximately $\sim 30 \%$ of GABAergic MSNs co-expressed the striatal markers dopamine- and cAMP-regulated neuronal phosphoprotein 32kDa (DARPP32) and COUP TF1-interacting protein 2 (CTIP2) (Figure 1A-D). There was no difference between healthy controls and SGCE MSNs when we quantitatively analyzed the immunofluorescence data. The mRNA expression of neuronal and striatal markers in MSNs showed a significant upregulation compared to the iPSC origin, but was not significantly different for control and SGCE MSNs (Figure 1E). The upregulation of glutamic acid decarboxylase (GAD67), transcription factor forkhead box protein P1 (FOXP1), which is associated with MSN maturation, and the mature neuronal marker microtubule-associated protein 2 (MAP2) confirmed the neuronal and mainly GABAergic phenotype of MSNs.

\subsection{Reduced Synaptic Density in SGCE MSNs}

The morphometric analyses of MSN neurites (using $\beta$-tubulin III (TUJ1)-staining, Figure 2A,B) displayed no differences between control and SGCE cell lines after analysis of parameters including neurite length, neurite area and number of neuronal somata per acquired image (Figure 2E-H). Furthermore, no difference of ramification between control and SGCE MSNs was detected by analyzing the number of attachment points of neurites at the soma and endpoints of neurites (Figure 2I). Interestingly, the quantification of GABApositive boutons in MSNs for the evaluation of synapse formation revealed a significantly reduced $(p<0.001)$ synaptic density in SGCE compared to control MSNs (Figure 2C,D,J).

\section{3. $\mathrm{Ca}^{2+}$ Signaling in $\mathrm{MSNs}$}

2.3.1. Elevated Basal Intracellular $\mathrm{Ca}^{2+}$ Levels and Lower Frequency of Spontaneous $\mathrm{Ca}^{2+}$ Signals in SGCE MSNs

A representative image of intracellular $\mathrm{Ca}^{2+}$ recordings of Fura-2 loaded SGCE MSNs is shown in Figure 3A. The SGCE MSNs showed significantly elevated basal intracellular $\mathrm{Ca}^{2+}$ levels compared to controls (SGCE $0.39 \pm 0.001$, control $0.35 \pm 0.001, p<0.001$, Figure 3B). A representative image of spontaneous $\mathrm{Ca}^{2+}$ transients of MSNs is shown in Figure 3C. The percentage of MSNs with spontaneous $\mathrm{Ca}^{2+}$ signals was not significantly different between SGCE $(30.2 \pm 2.8 \%)$ and control MSNs (34.8 $\pm 3.6 \%$, Figure 3D). However, the frequency (SGCE $0.157 \pm 0.011 \mathrm{~Hz}$, control $0.255 \pm 0.014 \mathrm{~Hz}, p<0.001$, Figure 3E) and the amplitudes (SGCE $0.038 \pm 0.003$, control $0.049 \pm 0.003, p<0.001$, Figure 3F) of spontaneous $\mathrm{Ca}^{2+}$ transients were significantly lower in SGCE compared to control MSNs. 
A

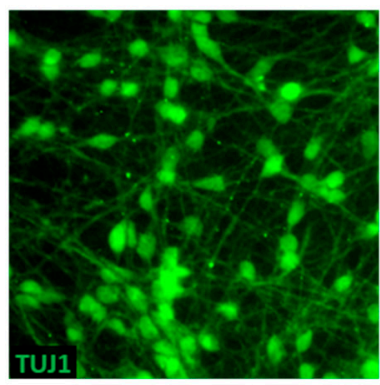

B

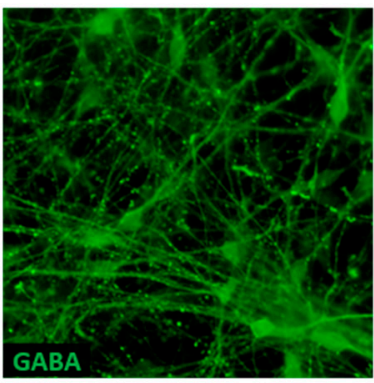

C

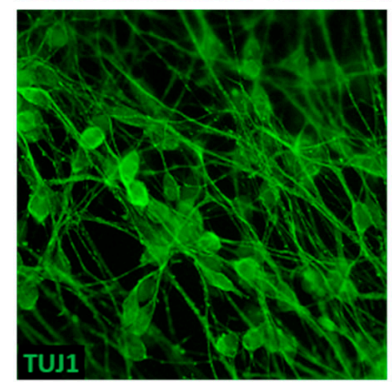

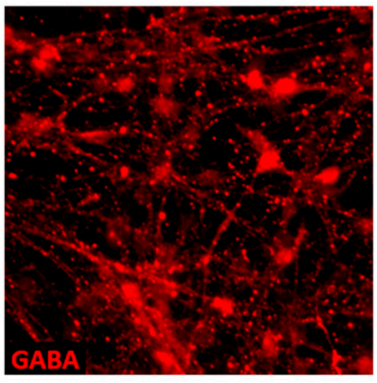
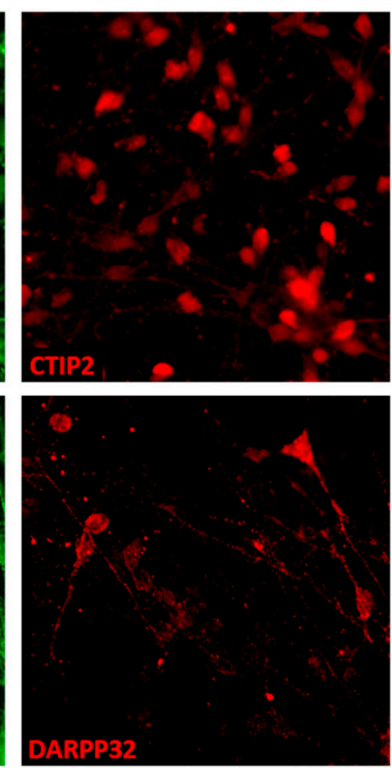
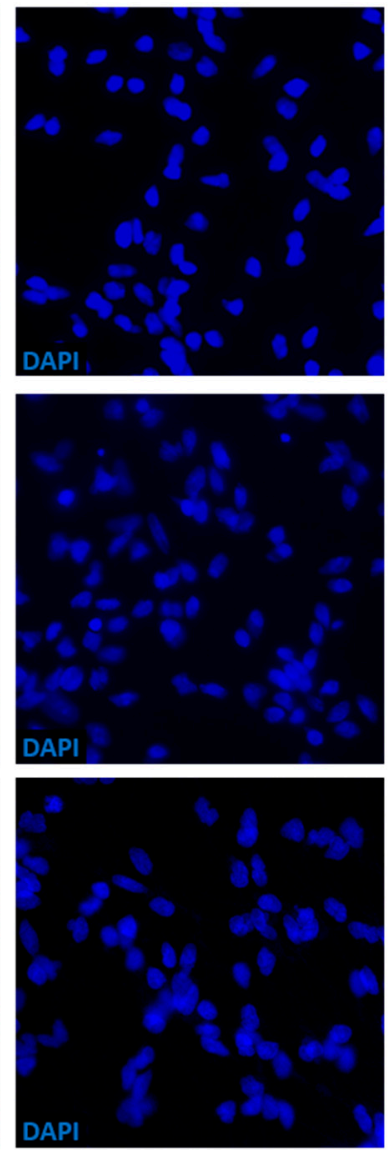
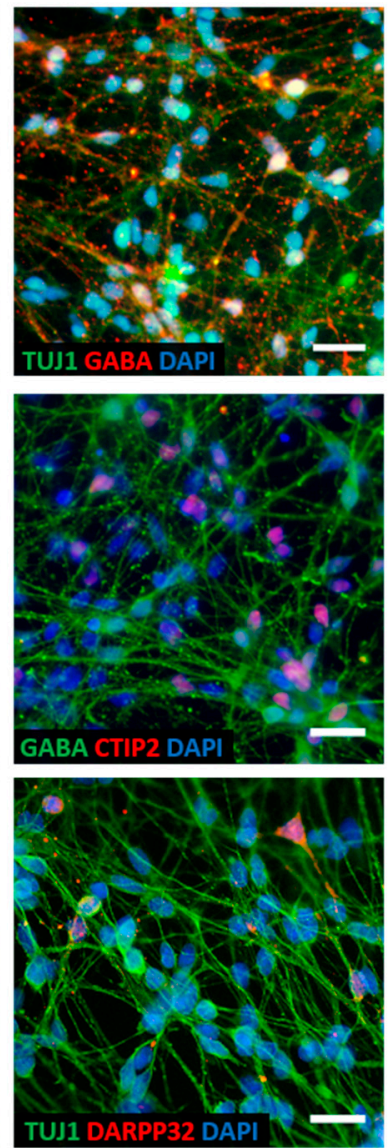

D

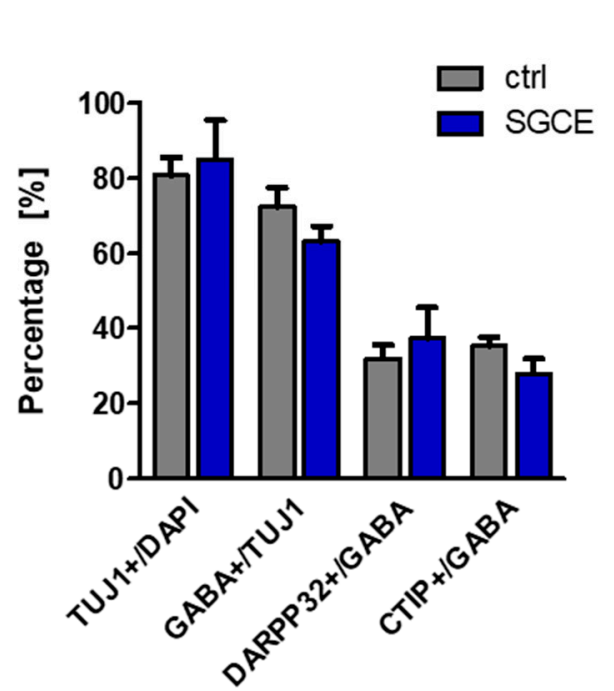

E
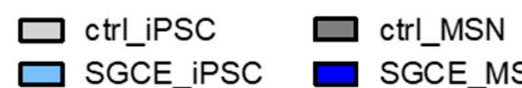

SGCE_MSN

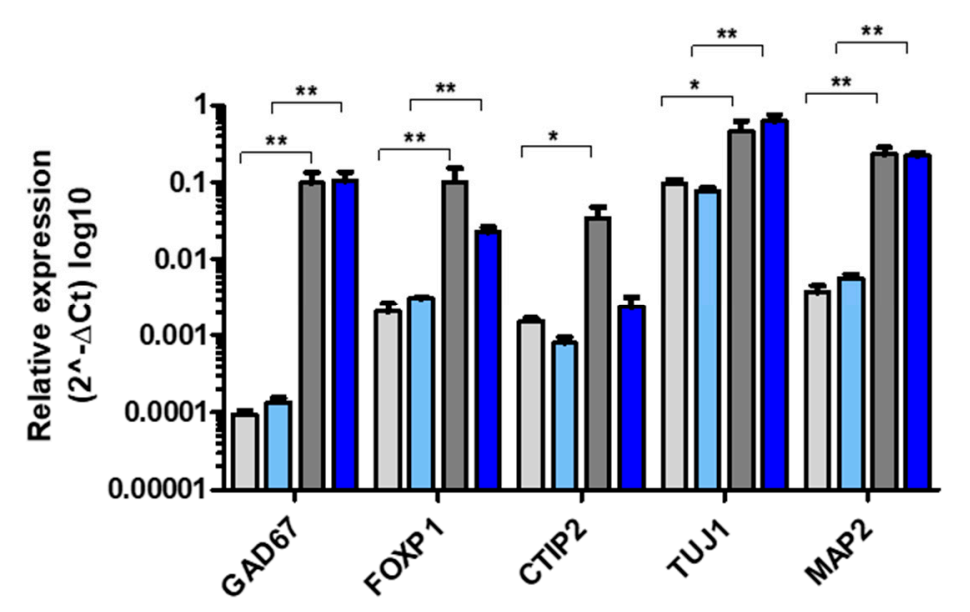

Figure 1. Differentiation of iPSCs derived from DYT-SGCE patients and healthy controls into striatal medium spiny neurons (MSNs). (A-C) Mature MSNs at day 70 (+/ - 7 days) of differentiation expressed the neuronal markers TUJ1, GABA and MSN-specific striatal markers DARPP32 and CTIP2 as shown by representative images of immunofluorescence stainings. Nuclei were stained with 4,6-diamidino-2-phenylindole (DAPI). Scale bar indicates $20 \mu \mathrm{m}$. (D) About $80 \%$ of DAPI-stained MSNs expressed the neuronal marker TUJ1, of which the vast majority were GABA-positive cells. About 30\% of GABA-positive cells co-expressed DARPP32 and CTIP2 showing terminal differentiation into striatal MSNs. Quantitative 
estimation of neuronal and striatal markers was similar for SGCE and control MSNs. Data are presented as means \pm SEM from at least two independent differentiations of each cell line. (E) Expression analysis of iPSCs and MSNs by quantitative real-time PCR. Compared to iPSCs, SGCE and control MSNs expressed elevated levels of markers for neuronal (FOXP1, TUJ1, MAP2), GABAergic (GAD67) and MSN-specific striatal origin (CTIP2). Expression of neuronal, GABAergic and MSN-specific markers was similar for SGCE and control MSNs. Data are presented as means \pm SEM in logarithmic scale $\left(\log _{10}\right)$ from three independent differentiations for SGCE and control lines ${ }^{*} p<0.05,{ }^{* *} p<0.01$, parametric t-test or nonparametric Mann-Whitney-U test).

control MSN

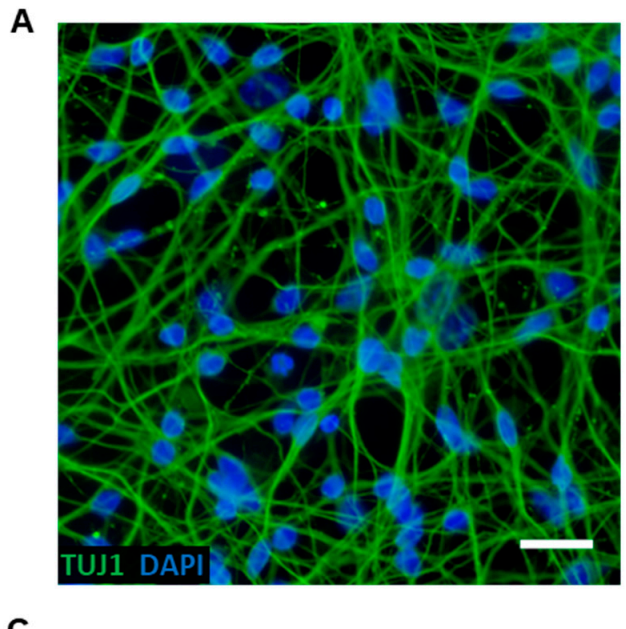

c

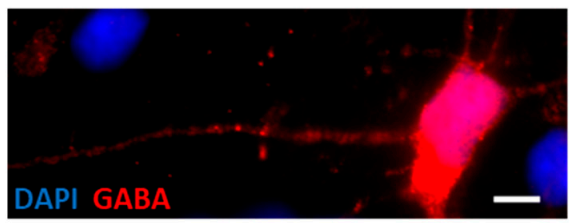

SGCE MSN

B

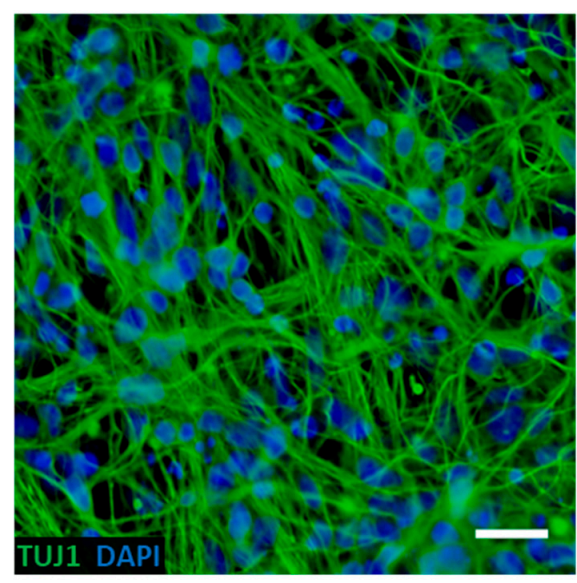

D

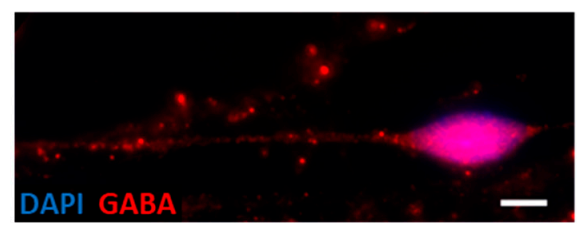

E

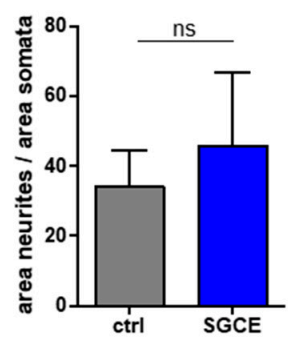

H

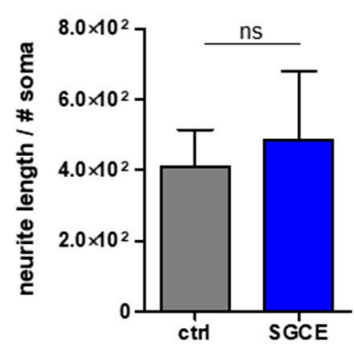

F

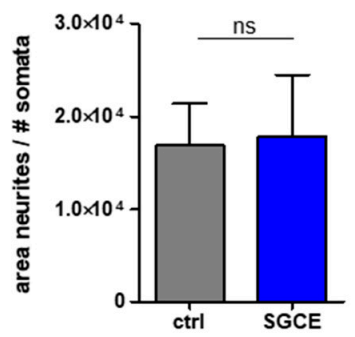

I

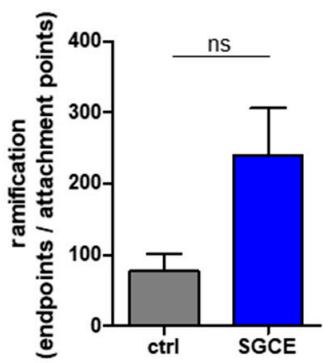

G

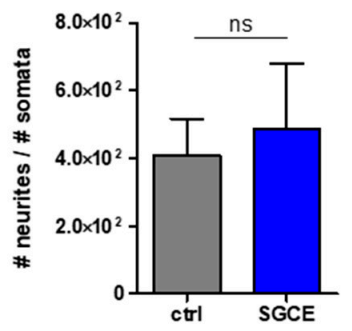

J

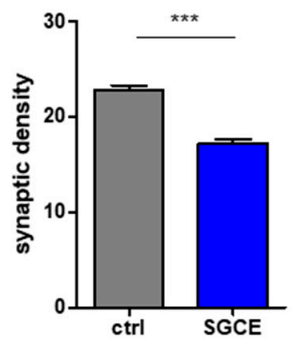

Figure 2. Neuronal morphology and GABAergic synaptic density of MSNs from DYT-SGCE patients and healthy controls. Control (A,C) and SGCE MSNs (B,D) were stained for neuronal markers TUJ1 and GABA to analyze neuronal morphology 
using ImageJ plugin Neurphology and quantify GABAergic synapses by ImageJ plugins SynapCountJ and NeuronJ. Nuclei were stained with DAPI. Scale bar indicates $20 \mu \mathrm{m}(\mathbf{A}, \mathbf{B})$ and $5 \mu \mathrm{m}(\mathbf{C}, \mathbf{D})$. Total neurite outgrowth parameters were quantified by normalization of neurites to somata. (E) The area of neurites was divided by the area of somata or $(\mathbf{F})$ the number of somata (\# somata). (G) The number of neurites (\# neurites) was divided by the number of somata (\# somata). (H) Total neurite length was obtained by neurite length divided by \# somata. All parameters were comparable between SGCE and control MSNs. (I) For the expression of total ramification, the number of endpoints of neurites was normalized to the number of attachment points at the soma. The SGCE MSNs showed a tendency of increased ramification compared to control MSNs. (J) SGCE MSNs showed a significantly lower amount of GABAergic synapses compared to controls. Abbreviation: ns, not significant. Data are presented as means \pm SEM from two to three independent differentiations for SGCE and control lines $\left({ }^{* * *} p<0.001\right.$, nonparametric Mann-Whitney-U test).

2.3.2. Elevated $\mathrm{Ca}^{2+}$ Amplitudes upon Glycine and Acetylcholine Application in SGCE MSNs

Representative traces of intracellular $\mathrm{Ca}^{2+}$ transients in Fura-2 loaded control and SGCE MSNs induced by separate application of acetylcholine $(100 \mu \mathrm{M})$ are shown in Figure 3G. Analysis of neurotransmitter-induced $\mathrm{Ca}^{2+}$ signaling revealed that SGCE MSNs showed significantly elevated amplitudes of $\mathrm{Ca}^{2+}$ transients in response to application of glycine (SGCE $0.14 \pm 0.013$, control $0.10 \pm 0.009, p<0.05$ ) and acetylcholine (SGCE $0.19 \pm 0.013$, control $0.27 \pm 0.023, p<0.01)$, whereas $\mathrm{Ca}^{2+}$ peaks elicited by GABA and glutamate application were similar in both groups (Figure $3 \mathrm{H}$ ). The percentage of cells responding with $\mathrm{Ca}^{2+}$ rises was similar upon individual neurotransmitter applications in both MSN groups (Figure 3I).

2.3.3. Blocking of $\mathrm{Ca}^{2+}$ Amplitudes after Application of Antagonists for Voltage-Gated $\mathrm{Ca}^{2+}$ Channels and Acetylcholine Receptors in MSNs

The viability and excitability of MSNs was evaluated by application of depolarizing $\mathrm{KCl}$ and was similar for control and SGCE MSNs. A representative trace of blocking $\mathrm{Ca}^{2+}$ transients in Fura-2 loaded SGCE MSN by verapamil $(100 \mu \mathrm{M})$ following applications of $\mathrm{KCl}(50 \mathrm{mM})$ is shown in Figure 3J. The drug verapamil inhibits voltage-gated $\mathrm{Ca}^{2+}$ channels nonspecifically and the blocking degree in percentage was significantly lower in SGCE compared to control MSNs (SGCE $9.7 \pm 0.6 \%, n=138$, control $29.9 \pm 2.8 \%, n=52$, $p<0.001$, Figure $3 \mathrm{~K})$. The blocking effect of atropine was significantly higher in SGCE compared to control MSNs (SGCE 32.0\% $\pm 2.1 \%, n=62$, control $11.2 \pm 3.3 \%, n=4, p<0.05$, Figure $3 \mathrm{~K})$. In contrast, the blocking degree of mecamylamine was markedly lower in SGCE MSNs (SGCE 26.4\% $\pm 1.8 \%, n=78$, control $36.6 \pm 2.0 \%, p<0.001$, Figure 3K).

\subsection{Expression of Voltage-Gated $\mathrm{Ca}^{2+}$ Channels and Ionotropic Receptor Subunits in MSNs}

Genomic expression levels of genes encoding voltage-gated $\mathrm{Ca}^{2+}$ channels $\mathrm{Ca}_{\mathrm{v}} 1.2-$ 1.3, $\mathrm{Ca}_{\mathrm{v}} 2.1-2.3$ and $\mathrm{Ca}_{\mathrm{v}} 3.1-3.3$ were comparable in both MSN groups (data not shown). The expression of $\mathrm{GABA}_{\mathrm{A}}$ receptor subunits $\alpha, \beta, \gamma$ and $\delta$ was not significantly different in SGCE and control MSNs. All MSNs showed predominant expression of synaptic $\mathrm{GABA}_{\mathrm{A}}$ receptor subunits, particularly $\beta 3$ followed by $\alpha 2$ and $\alpha 3$, whereas subunits typical for extra-synaptic receptors $(\alpha 4, \alpha 6$ and $\delta$ ) were barely expressed in SGCE MSNs (Figure $4 \mathrm{~A}$ ). The expression of muscarinic acetylcholine receptor ( $\mathrm{mAChR}$ ) subunit $\mathrm{M}_{1}$ was significantly lower for SGCE MSNs compared to control MSNs. The genomic expression of mAChR subunits $\mathrm{M}_{2}-\mathrm{M}_{5}$ (encoded by genes CHRM2-CHRM5) was similar in SGCE and control MSNs with lowest expression of CHRM5 (Figure 4B). Levels of transcripts encoding for nicotinic acetylcholine receptor (nAChR) subunits $\alpha$ (3-7), $\beta 2, \beta 4$ (encoded by genes CHRNA3-CHRNA7, CHRNB2 and CHRNB4) were equal in SGCE and control MSNs (Figure $4 \mathrm{C}$ ). Predominantly, CHRNA4 and CHRNA5 were expressed in MSNs. 
A

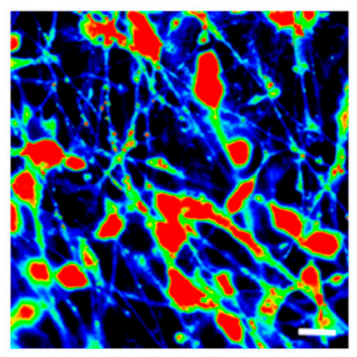

D

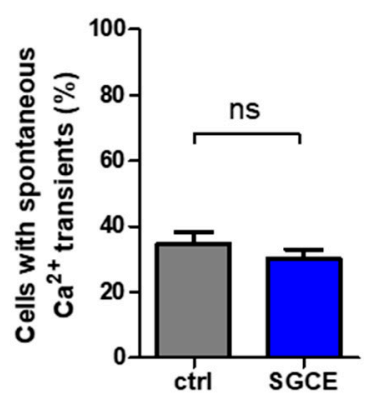

B

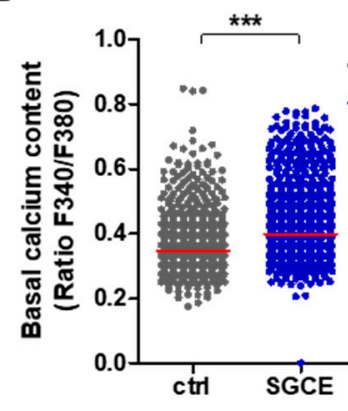

E

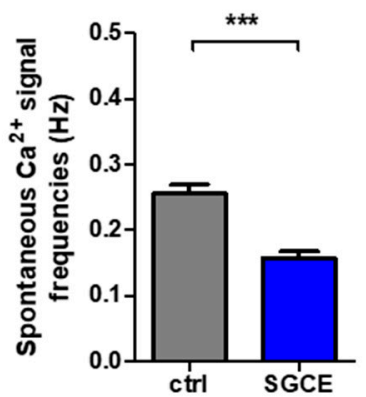

C

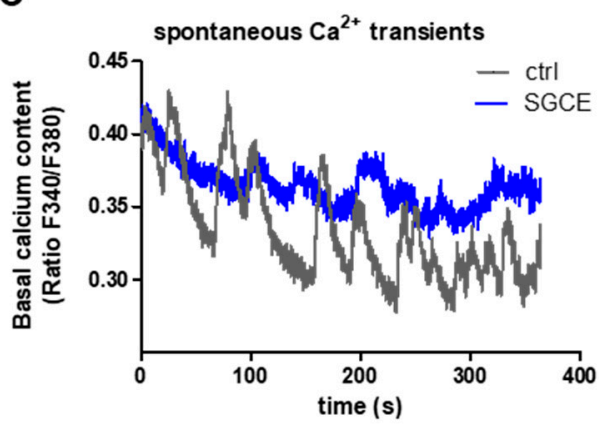

$\mathbf{F}$

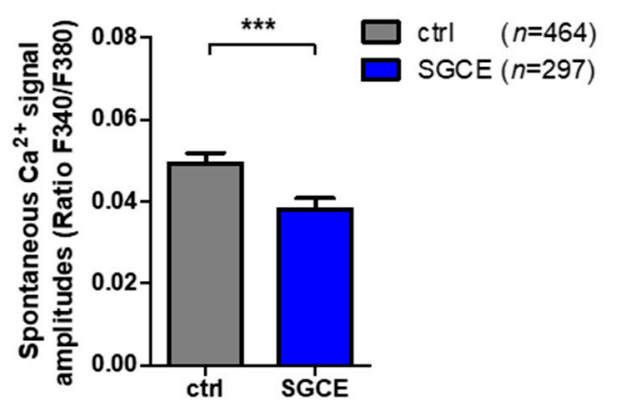

G

H

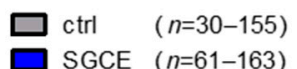

I

口 ctrl (n=30-155)

口 SGCE (n=61-163)
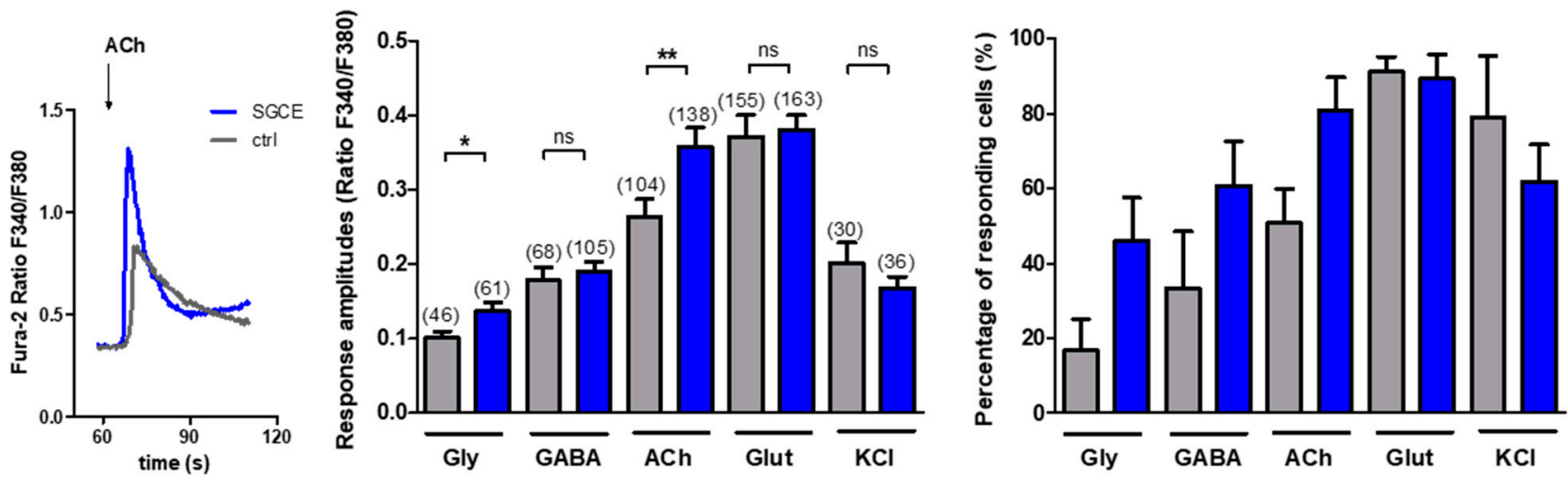

J

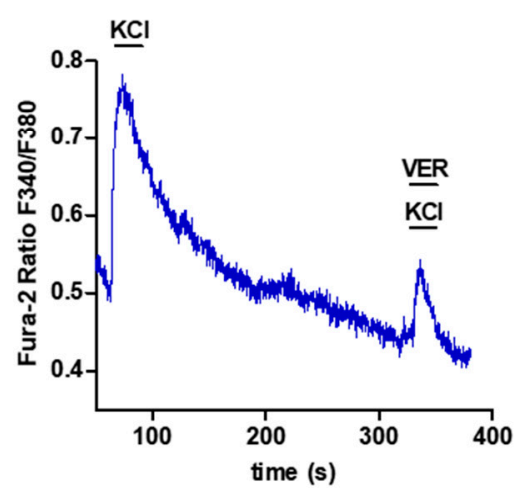

K

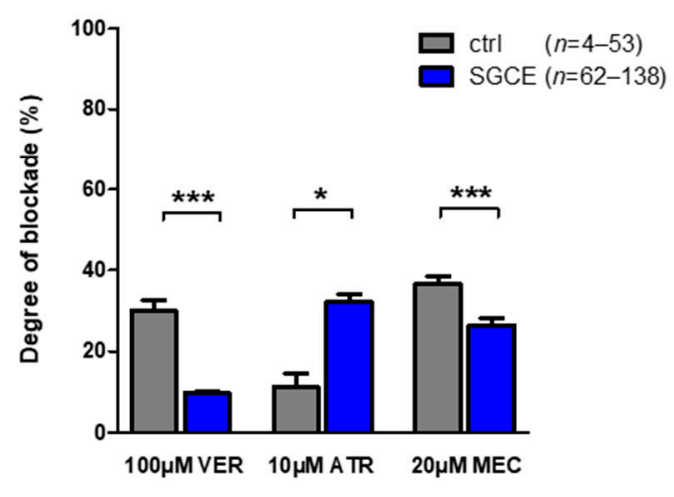

Figure 3. Spontaneous intracellular calcium $\left(\mathrm{Ca}^{2+}\right)$ dynamics, neurotransmitter-induced $\mathrm{Ca}^{2+}$ signaling and inhibition of voltage-gated $\mathrm{Ca}^{2+}$ channels and acetylcholine receptors in MSNs derived from DYT-SGCE patients and healthy controls. 
Intracellular $\mathrm{Ca}^{2+}$ transients are presented as ratios of the fluorescence signals obtained at 340 and $380 \mathrm{~nm}\left(\mathrm{~F}_{340} / \mathrm{F}_{380}\right)$. (A) Representative image of $\mathrm{Ca}^{2+}$ recordings in SGCE MSNs loaded with Fura-2. Scale bar indicates $30 \mu \mathrm{m}$. (B) Basal intracellular $\mathrm{Ca}^{2+}$ levels were significantly elevated in SGCE $(n=1067)$ compared to control MSNs $\left(n=1183,{ }^{* * *} p<0.001\right.$, nonparametric Mann-Whitney-U test). (C) Representative traces of spontaneous $\mathrm{Ca}^{2+}$ peaks of control and SGCE MSNs. (D) The percentage of cells showing spontaneous $\mathrm{Ca}^{2+}$ transients was not significantly different between both MSN groups ( $\sim 38 \%$, unpaired $t$-test). (E) Spontaneous $\mathrm{Ca}^{2+}$ signal frequencies ${ }^{* * *} p<0.001$, nonparametric Mann-Whitney-U test) and (F) amplitudes were significantly lower in SGCE $(n=297)$ compared to control MSNs $(n=464, * * *<0.001$, nonparametric Mann-Whitney-U test). Data are presented as means \pm SEM from at least three independent differentiations for SGCE and control lines. (G) Representative traces of intracellular $\mathrm{Ca}^{2+}$ changes of Fura-2 loaded control and SGCE neurons induced by separate application of acetylcholine $(\mathrm{ACh}, 100 \mu \mathrm{M})$. (H) Cytosolic $\mathrm{Ca}^{2+}$ response amplitudes upon separate applications of the neurotransmitters glycine (Gly,100 $\mu \mathrm{M}), \gamma$-aminobutyric acid (GABA, $100 \mu \mathrm{M})$, acetylcholine (ACh, $100 \mu \mathrm{M})$ and glutamate (Glut, $50 \mu \mathrm{M}$ ) normalized to the basal $\mathrm{Ca}^{2+}$ level of MSNs ( $n=$ number of cells) showed significantly higher $\mathrm{Ca}^{2+}$ peaks during application of glycine and acetylcholine in SGCE compared to control MSNs $\left({ }^{*} p<0.05,{ }^{* *} p<0.001\right.$, nonparametric Mann-Whitney-U test). (I) Percentage of cells responding to neurotransmitter applications with $\mathrm{Ca}^{2+}$ rises shown in subfigure $\mathrm{H}$ was similar in SGCE and control MSNs (nonparametric Mann-Whitney-U test). (J) Representative trace of intracellular $\mathrm{Ca}^{2+}$ changes in a Fura-2 loaded SGCE MSN induced by separate application of $50 \mathrm{mM} \mathrm{KCl}$ followed by $\mathrm{KCl}$ and verapamil (100 $\mu \mathrm{M}$, VER). (K) Significantly lower blockade of $\mathrm{KCl}$-induced $\mathrm{Ca}^{2+}$ transients by separate application of verapamil (100 $\mu \mathrm{M}$, blocks voltage-gated $\mathrm{Ca}^{2+}$ channels) in SGCE MSNs (control $n=53,29.9 \%$ blockade; SGCE $n=138$, $9.7 \%$ blockade). Application of either atropine $(10 \mu \mathrm{M}, \mathrm{ATR}$, muscarinic acetylcholine receptor antagonist, control $n=4$, $11.2 \%$ blockade; SGCE $n=62,32.0 \%$ blockade $)$ or mecamylamine $(20 \mu \mathrm{M}$, MEC, nicotinic acetylcholine receptor antagonist, control $n=48,36.6 \%$ blockade; SGCE $n=78,26.4 \%$ blockade) suppressing $\mathrm{Ca}^{2+}$ peaks evoked by $100 \mu \mathrm{M}$ acetylcholine application in MSNs. Data are presented as means \pm SEM from at least three independent differentiations for SGCE and control lines for neurotransmitter applications. Abbreviation: ns, not significant. Data were recorded from two independent differentiations for blocking of voltage-gated $\mathrm{Ca}^{2+}$ channels and acetylcholine receptors during $\mathrm{Ca}^{2+}$ signaling $\left({ }^{*} p<0.05\right.$, ${ }^{* *} p<0.01,{ }^{* * *} p<0.001$, nonparametric Mann-Whitney-U test).

\subsection{Properties of Voltage-Gated Ion Channels, Synaptic Activity and Action Potentials in MSNs}

Whole-cell patch-clamp recordings from MSNs of DYT-SGCE patients and healthy controls were performed to assess voltage-gated ion channels, action potential properties and synaptic activity (Table 1). SGCE and control MSNs showed sodium inward and potassium outward currents upon depolarizing steps in increments of $10 \mathrm{mV}$ from a holding potential of -70 to $40 \mathrm{mV}$ (Figure $5 \mathrm{~A}$ ). After normalization of ion current amplitudes for individual cell sizes based on capacitances of the cell membrane (pA/pF), both groups did not significantly differ (Figure 5B).

\subsubsection{Larger mPSC Amplitudes in SGCE MSNs}

Measurements of spontaneous synaptic activity of MSNs revealed that the percentage of cells with miniature postsynaptic currents (mPSCs) was lower in SGCE (79.7\%) compared to control MSNs (98.2\%), however, without significant difference (Figure 5C,D). The mPSC frequencies were similar in both groups, while mPSC amplitudes were significantly higher in SGCE than in control MSNs (SGCE $29.8 \pm 2.4 \mathrm{pA}$, control $21.9 \pm 1.8 \mathrm{pA}, p=0.011$, Figure 5E,F).

\subsubsection{Elevated Amplitudes of Evoked Action Potentials in SGCE MSNs}

Single action potentials (APs) elicited by depolarizing current injections from a holding potential of approximately $-70 \mathrm{mV}$ were fired from the majority of control $(68 \%)$ and SGCE MSNs (71\%, Table 1, Figure 6A). The percentage of MSNs with repetitive APs after evoked spiking was also similar for SGCE (29\%) and control group (32\%, Table 1, Figure 6A,C,D). The amplitudes of evoked APs were significantly $(p<0.001$, Figure $6 \mathrm{~B})$ elevated for SGCE $(74.3 \pm 2.6 \mathrm{mV})$ compared to control MSNs $(57.2 \pm 3.7 \mathrm{mV})$. In addition, AP duration was significantly shorter in SGCE compared to control MSNs (SGCE $2.3 \pm 0.1 \mathrm{~ms}$, control $3.2 \pm 0.4 \mathrm{~ms}, p<0.05$, Table 1). The amplitude of after-hyperpolarization (AHP) was significantly elevated in SGCE MSNs (SGCE $8.2 \pm 0.9 \mathrm{mV}$, control $6.0 \pm 1.3 \mathrm{mV}, p<0.05$, 
Table 1), whereas the time to peak AHP was comparable (SGCE $26.0 \pm 3.1 \mathrm{~ms}$, control $20.9 \pm 1.3 \mathrm{~ms}$, Table 1). The number of SGCE cells with spontaneous APs was higher, but not significantly different compared to control MSNs (SGCE $62.3 \pm 13.9 \%$, control $48.0 \pm 13.3 \%$, Figure $6 \mathrm{E}, \mathrm{F}$ ). Furthermore, the frequency (SGCE $0.60 \pm 0.1 \mathrm{~Hz}$, control $0.49 \pm 0.07 \mathrm{~Hz}$ ) and amplitude of spontaneous APs was similar for both groups (SGCE $43.3 \pm 2.3 \mathrm{mV}$, control $46.5 \pm 3.2 \mathrm{mV}$, Figure $6 \mathrm{G}, \mathrm{H})$.

A

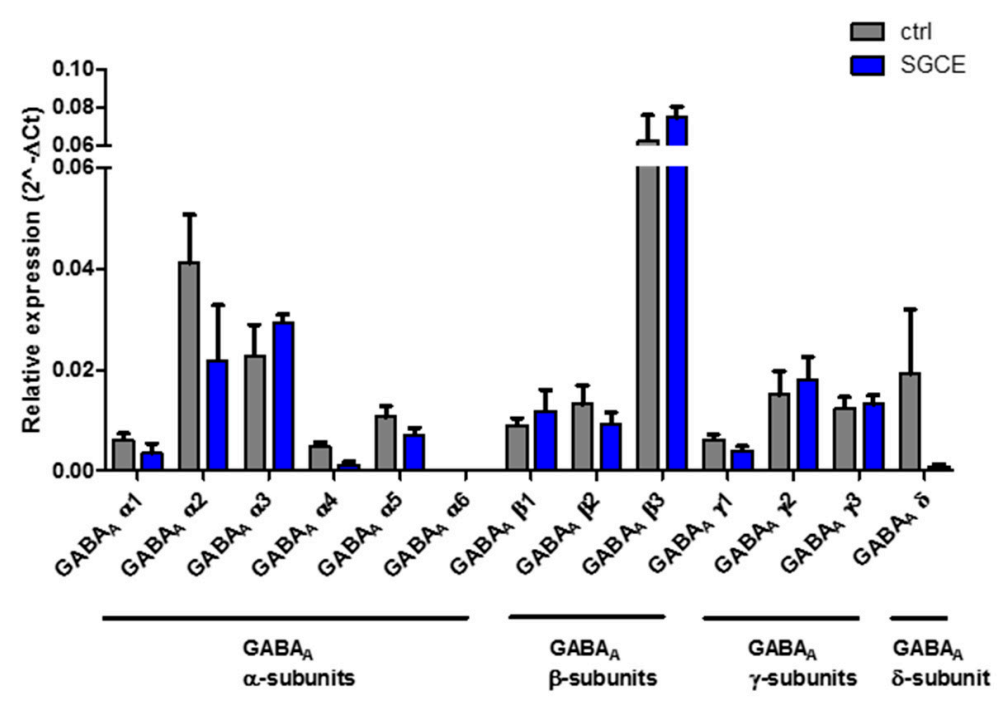

B

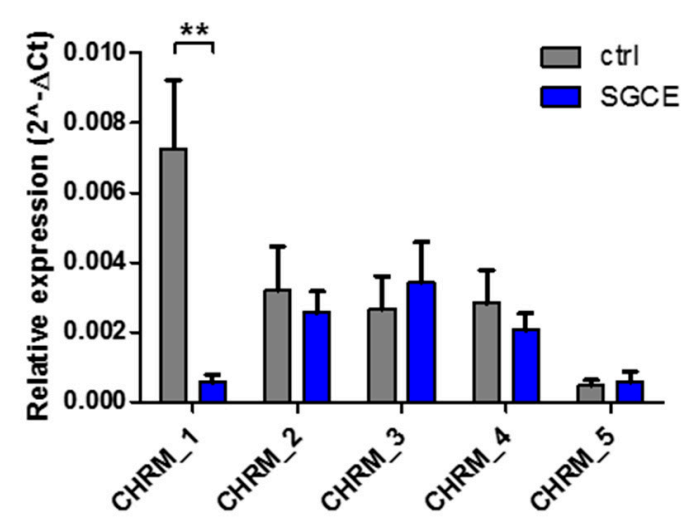

C

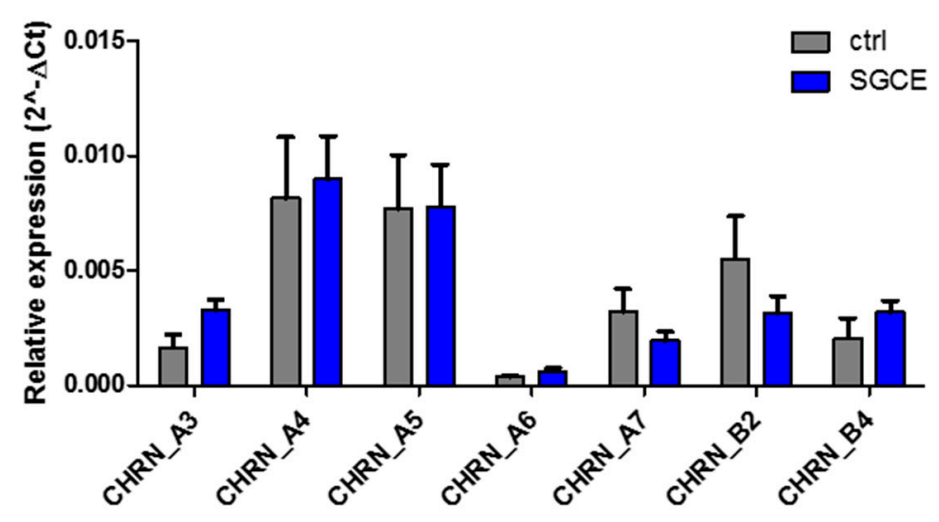

Figure 4. Expression analysis of ionotropic receptor subunits in MSNs from DYT-SGCE patients and healthy controls by quantitative real-time PCR. (A) Expression of genes encoding $\gamma$-aminobutyric acid type A $\left(\mathrm{GABA}_{\mathrm{A}}\right)$ receptor subunits $\alpha$ (1-6), $\beta(1-3), \gamma(1-3)$ and $\partial$ was similar in SGCE compared to control MSNs. (B) Expression of the muscarinic acetylcholine receptor subunit $\mathrm{M}_{1}$ (encoded by CHRM1) was significantly lower in SGCE MSNs, whereas the expression of the subunits $\mathrm{M}_{2}-\mathrm{M}_{5}$ (encoded by CHRM1-CHRM5) was similar in SGCE and control MSNs. (C) Expression of nicotinic acetylcholine receptor subunits $\alpha$ (3-7), $\beta 2$ and $\beta 4$ (encoded by CHRNA3-CHRNA7, CHRNB2, CHRNB4) was not significantly different in SGCE and control MSNs. Data are presented as means \pm SEM from three independent differentiations for SGCE and control lines $\left({ }^{* *} p<0.01\right.$, nonparametric Mann-Whitney-U test). 
Table 1. Whole-cell patch-clamp recordings of iPSC-derived MSNs from two DYT-SGCE patients and two healthy controls.

\begin{tabular}{|c|c|c|c|c|c|c|}
\hline & Control & & & DYT-SGCE & & \\
\hline Functional Properties & Control_1 $(n=21)$ & Control_2 $(n=14)$ & Control $(n=35)$ & SGCE_1 $(n=24)$ & SGCE_2 $(n=19)$ & SGCE $(n=43)$ \\
\hline $\mathrm{I}_{\mathrm{Na}}$ max. amplitudes $(\mathrm{pA} / \mathrm{pF})$ & $-106.2 \pm 18.8$ & $-126.6 \pm 19.5$ & $-116.4 \pm 10.2$ & $-85.75 \pm 12.3$ & $-92.78 \pm 14.72$ & $-89.27 \pm 3.52$ \\
\hline $\mathrm{I}_{\mathrm{K}}$ max. amplitudes $(\mathrm{pA} / \mathrm{pF})$ & $148.4 \pm 30.2$ & $125.3 \pm 26.3$ & $136.9 \pm 11.5$ & $103.8 \pm 13.1$ & $128.4 \pm 19.3$ & $116.1 \pm 12.3$ \\
\hline Resting membrane potential $(\mathrm{mV})$ & $-39.1 \pm 2.2$ & $-23.3 \pm 3.1$ & $-32.9 \pm 2.2$ & $-33.4 \pm 1.8$ & $-38.33 \pm 3.0$ & $-35.7 \pm 1.7$ \\
\hline Membrane capacitance $(\mathrm{pF})$ & $30.5 \pm 3.9$ & $17.8 \pm 3.1$ & $25.4 \pm 2.8$ & $27.8 \pm 4.6$ & $28.2 \pm 5.1$ & $28.0 \pm 3.4$ \\
\hline Input resistance (MOhm) & $996.3 \pm 275.2$ & $553.9 \pm 195.2$ & $819.4 \pm 184.2$ & $415.1 \pm 74.6$ & $566.1 \pm 82.1$ & $481.8 \pm 55.8$ \\
\hline Cells with single evoked APs (\%) & $48.9 \pm 24.8$ & $87.5 \pm 12.5$ & $68.2 \pm 15.1$ & $68.6 \pm 2.0$ & $72.2 \pm 14.7$ & $70.8 \pm 8.1$ \\
\hline Cells with repetitive evoked APs (\%) & $51.1 \pm 24.8$ & $12.5 \pm 12.5$ & $31.8 \pm 15.1$ & $31.4 \pm 2.0$ & $22.2 \pm 14.7$ & $25.9 \pm 8.4$ \\
\hline Amplitude $(\mathrm{mV})$ of evoked APs & $56.9 \pm 5.1$ & $57.8 \pm 5.0$ & $57.2 \pm 3.7$ & $75.8 \pm 3.4$ & $72.5 \pm 4.1$ & $74.3 \pm 2.6^{* * *}$ \\
\hline Duration (ms) of evoked APs & $3.0 \pm 0.4$ & $3.5 \pm 0.7$ & $3.2 \pm 0.4$ & $2.4 \pm 0.2$ & $2.3 \pm 0.1$ & $2.3 \pm 0.1 *$ \\
\hline AHP amplitude $(\mathrm{mV})$ & $7.6 \pm 1.9$ & $3.2 \pm 0.7$ & $6.0 \pm 1.3$ & $8.3 \pm 1.1$ & $8.1 \pm 1.4$ & $8.2 \pm 0.9 *$ \\
\hline Time to peak AHP (ms) & $21.6 \pm 4.0$ & $19.5 \pm 3.0$ & $20.9 \pm 2.7$ & $21.3 \pm 2.0$ & $31.9 \pm 6.4$ & $26.0 \pm 3.1$ \\
\hline Cells with spontaneous APs (\%) & $58.5 \pm 20.3$ & $37.5 \pm 19.1$ & $48.0 \pm 13.3$ & $74.5 \pm 7.8$ & $54.2 \pm 23.2$ & $62.3 \pm 13.9$ \\
\hline Frequency of spontaneous APs $(\mathrm{Hz})$ & $0.50 \pm 0.10$ & $0.47 \pm 0.10$ & $0.49 \pm 0.07$ & $0.52 \pm 0.12$ & $0.72 \pm 0.16$ & $0.60 \pm 0.10$ \\
\hline Amplitude of spontaneous APs (mV) & $49.0 \pm 3.1$ & $42.7 \pm 6.7$ & $46.5 \pm 3.2$ & $46.7 \pm 2.9$ & $38.9 \pm 3.4$ & $43.3 \pm 2.3$ \\
\hline Cells with miniature PSCs (\%) & $96.3 \pm 3.7$ & $100.0 \pm 0.0$ & $98.2 \pm 1.9$ & $75.0 \pm 25.0$ & $82.8 \pm 8.6$ & $79.7 \pm 9.4$ \\
\hline Miniature PSC frequencies (Hz) & $3.2 \pm 0.71$ & $2.4 \pm 0.63$ & $2.9 \pm 0.48$ & $2.0 \pm 0.37$ & $2.0 \pm 0.53$ & $2.0 \pm 0.30$ \\
\hline
\end{tabular}

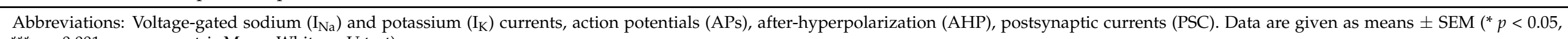
$* * * p<0.001$, nonparametric Mann-Whitney-U test). 
A

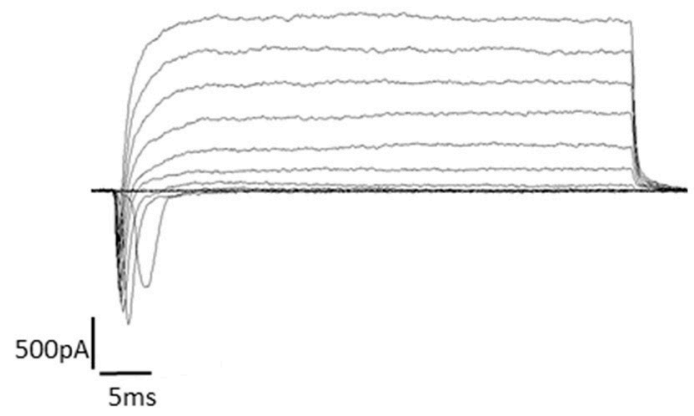

B

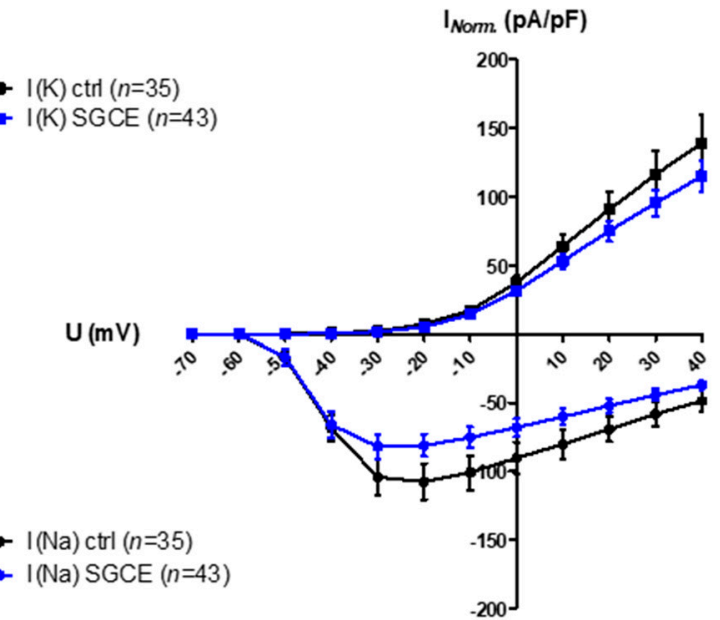

C

control MSN

SGCE MSN

H.

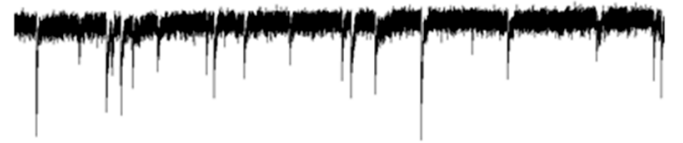

20pA

$2.5 \mathrm{~s}$

D

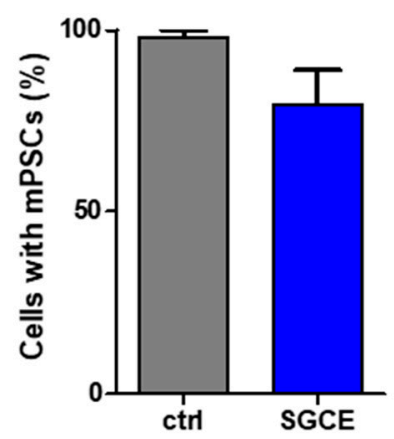

E

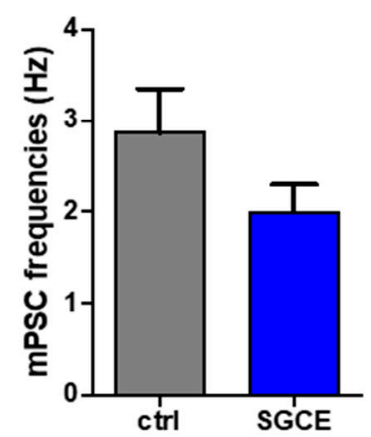

$\mathbf{F}$

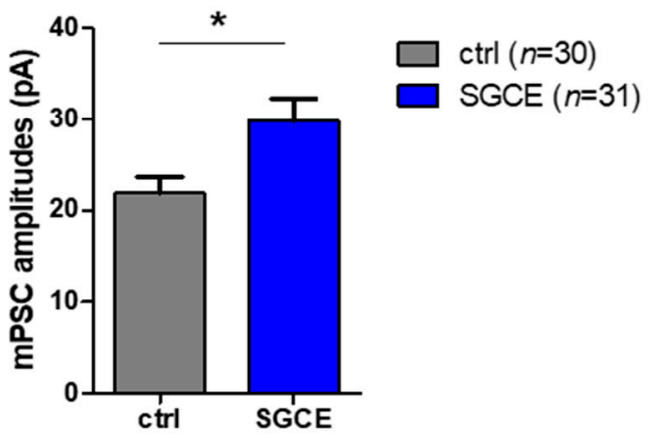

Figure 5. Voltage-gated ion currents and action potential (AP) recordings of MSNs derived from DYT-SGCE patients and healthy controls. (A) Voltage-gated sodium inward and potassium outward currents of SGCE MSN at day 70 in vitro were recorded in whole-cell voltage-clamp mode by depolarizing steps in increments of $10 \mathrm{mV}$ from a holding potential of -70 to $40 \mathrm{mV}$. (B) Ion currents normalized for individual cell sizes based on capacitances of the cell membrane (pA/pF) were not significantly different between SGCE $(n=43)$ and control MSNs $(n=35$, two-way ANOVA with Bonferroni post-hoc test). (C) Traces of miniature postsynaptic currents (mPSC), indicating spontaneous synaptic events from MSN afferents, were recorded in whole-cell voltage-clamp mode at a holding potential of $-70 \mathrm{mV}$. (D) Percentage of cells with mPSCs and (E) mPSC frequencies were not significantly different for SGCE $(n=31)$ and control MSNs $(n=30$, nonparametric Mann-Whitney-U test). (F) The mPSC amplitudes were significantly higher in SGCE compared to control MSNs ( $p<0.05$, nonparametric Mann-Whitney-U test). Data are presented as means \pm SEM from at least two independent differentiations for SGCE and control lines. 
A
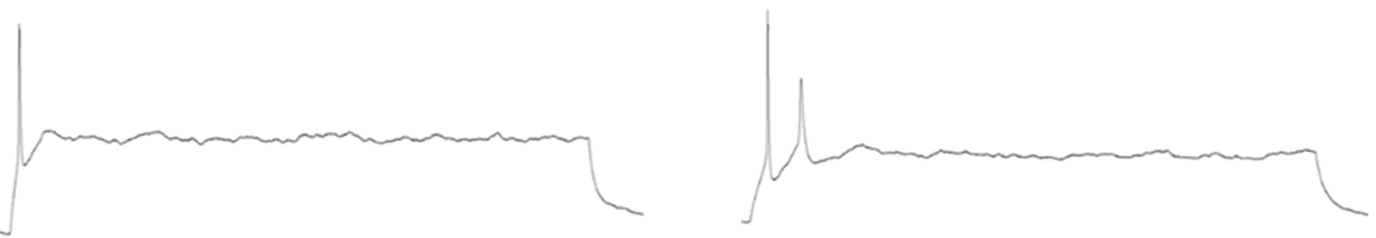

$10 \mathrm{mVl}$

$\overline{100 \mathrm{~ms}}$

B

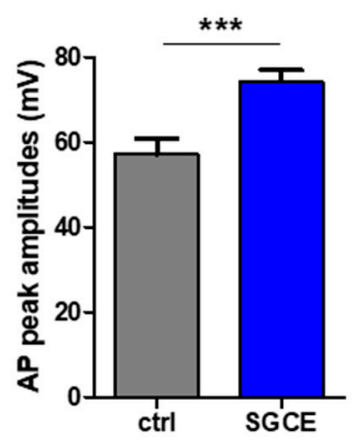

C

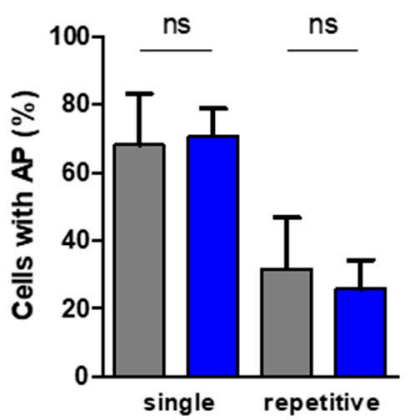

D

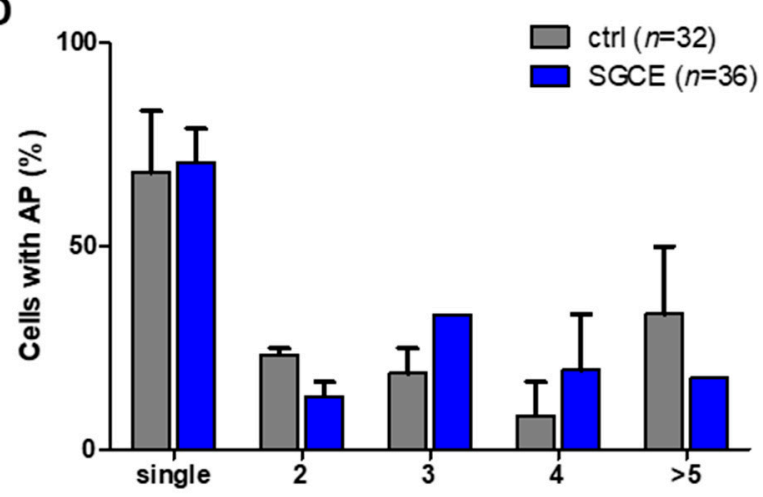

E

control MSN

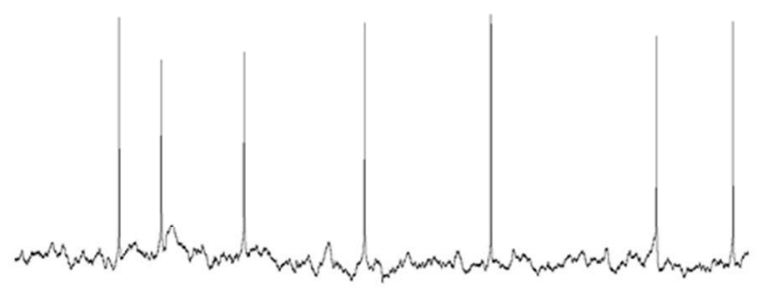

$10 \mathrm{mV}$

1s

$\mathbf{F}$

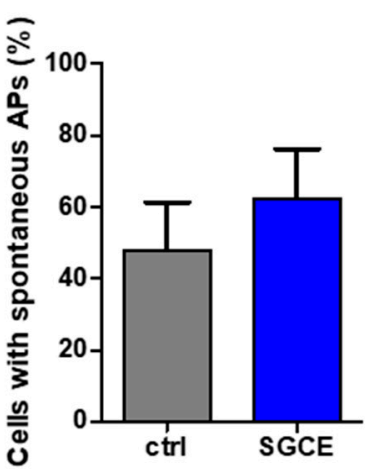

G

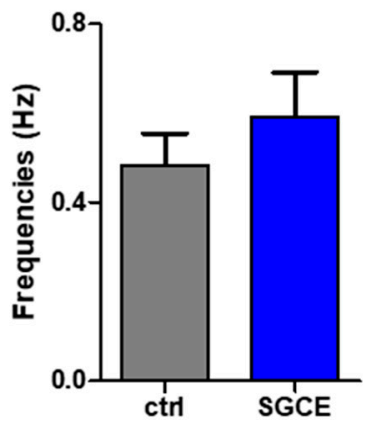

SGCE MSN

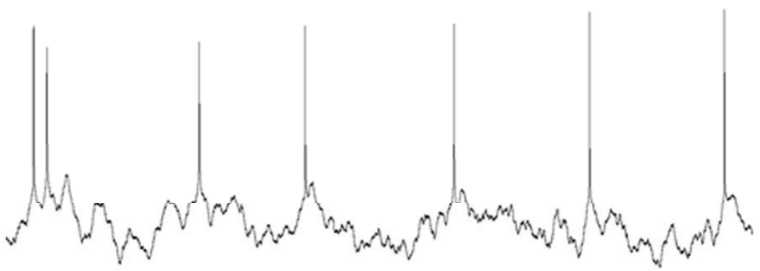

H

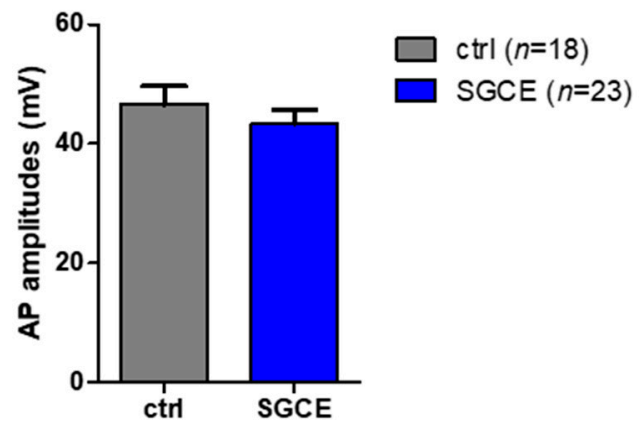

Figure 6. Evoked and spontaneous action potentials (APs) of MSNs from DYT-SGCE patients and healthy controls. (A) Example of SGCE MSNs firing single and repetitive APs upon depolarization in current-clamp mode from a holding potential of approximately $-70 \mathrm{mV}$. (B) Evoked AP amplitudes were significantly elevated in SGCE $(n=36)$ compared to 
control MSNs $\left(n=32,{ }^{* * *} p<0.001\right.$, unpaired $t$-test). (C) Percentages of cells with single or repetitive APs were not significantly different between MSNs of both groups (nonparametric Mann-Whitney-U test). (D) Percentages of neurons with single or multiple $(2,3,4, \geq 5)$ APs were not significantly different between MSNs of both groups (two-way ANOVA with Bonferroni post hoc test). (E) Spontaneous AP firing was measured at a holding potential of approximately $-60 \mathrm{mV}$. (F) Percentage of cells with spontaneous APs, $(\mathbf{G})$ frequencies and $(\mathbf{H})$ amplitudes of spontaneous APs were comparable for SGCE $(n=23)$ and control MSNs ( $n=18$, nonparametric Mann-Whitney-U test). Abbreviation: ns, not significant. Data are presented as means \pm SEM from at least two independent differentiations for SGCE and control lines.

\section{Discussion}

To better understand the pathophysiology of DYT-SGCE, we investigated iPSCderived striatal MSNs of DYT-SGCE patients and healthy controls after 70 days of differentiation adapting previously established in vitro iPSC differentiation protocols towards striatal neurons $[37,38]$. Our preliminary data showed in patient neurons the selective expression of the mutated paternal SGCE allele due to maternal imprinting and dramatically reduced SGCE protein levels confirming the suitability of this iPSC model for myoclonusdystonia research [19].

In calcium imaging recordings, the basal intracellular calcium levels were significantly elevated in SGCE-mutant compared to control MSNs. Besides, the frequency and amplitude of spontaneous calcium signals were lower in SGCE MSNs. A previous investigation demonstrated that accumulated intracellular $\mathrm{Ca}^{2+}$ accompanied the absence of dystrophin in neurons [39]. It can be assumed that the same processes might occur when a protein of the dystrophin-glycoprotein-complex other than dystrophin, such as $\varepsilon$-sarcoglycan, is affected [23]. Therefore, calcium homeostasis is likely to play an important role in the course of this genetic form of myoclonus-dystonia. $\mathrm{Ca}^{2+}$ signals are less suppressed in SGCE than in control MSNs after unspecific blockade of voltage-gated $\mathrm{Ca}^{2+}$ channels by application of verapamil, although the expression of these channels is comparable. Two case reports described that myoclonic dystonia [40] or multifocal myoclonus [41] could be induced by verapamil.

Recordings of calcium signaling after neurotransmitter application revealed elevated calcium amplitudes upon glycine and acetylcholine applications in SGCE MSNs. $\mathrm{Ca}^{2+}$ signals evoked by acetylcholine were significantly less blocked by the nicotinic acetylcholine receptor antagonist mecamylamine in SGCE compared to control MSNs. In contrast, the muscarinic acetylcholine receptor antagonist atropine inhibited significantly stronger after acetylcholine application in SGCE MSNs. These results may suggest an increased signaling via the muscarinic acetylcholine receptor in DYT-SGCE MSNs compared to healthy controls, which could be accompanied by a reduced transmission via the nicotinic acetylcholine receptor. In line with this, a medication with anticholinergic drugs such as trihexyphenidyl that is a muscarinic acetylcholine receptor blocker, could improve motor symptoms in DYT-SGCE [42-45]. So it could be hypothesized that cholinergic signaling, especially via muscarinic acetylcholine receptors, plays an important role in DYT-SGCE. In striatal MSNs of DYT-TOR1A, anticholinergic drugs inhibiting the M1 muscarinic acetylcholine receptor, such as trihexyphenidyl, have been shown to improve symptoms [46]. Besides, it was demonstrated that extrapyramidal syndromes induced by antipsychotic drugs could be treated successfully by selective M1 antagonists [47].

However, gene expression analysis of transcripts encoding for neuronal muscarinic acetylcholine receptor (mAChR) subunits revealed a significantly lower expression of CHRM1 (encoding for $\mathrm{mAChR}$ subunit $\mathrm{M}_{1}$ ) in patient-derived SGCE MSNs compared to the control group. In contrast, a previous study using a dystonic hamster model linked increased expression of the acetylcholine receptor subunit $\mathrm{M}_{1}$ in the striatum to the involvement of the cholinergic system resulting in abnormal striatal plasticity [48]. As it would have been expected from previous studies, CHRM5 was expressed very low in human MSNs whereas transcripts encoding for other mAChR subtypes $\mathrm{M}_{2}-\mathrm{M}_{4}$ were more abundant $[44,49]$. The discrepancy between elevated acetylcholine-induced $\mathrm{Ca}^{2+}$ signals and decreased expression of CHRM1 in SGCE MSNs may in part be explained by post- 
translational changes of acetylcholine receptors resulting in a compensatory higher $\mathrm{Ca}^{2+}$ influx. Regarding the expression of nicotinic acetylcholine receptor subunits (nAChRs), comparable ratios as known from the literature were also detected in our iPSC-derived MSNs, with lower expression levels of CHRNA6 and higher levels of CHRNA5 (encoding for $n A C h R$ subunits $\alpha 6$ and $\alpha 5$ ) in relation to iPSC-derived neurons comprising primarily of GABAergic and glutamatergic cells [50]. The most widely expressed neuronal nAChR subtype in the brain is heteromeric $\alpha 4 \beta 2$ [44,51]. Possibly, altered afferents of striatal cholinergic interneurons or posttranslational modifications of acetylcholine receptors in SGCE MSNs may account for some of the differences in cholinergic signaling. In line with this, changes in acetylcholine receptors and release were seen in the hippocampus of dystrophin-deficient mice [52,53]. A favorable pathogenic hypothesis is that DYT-SGCE may be caused by altered neuronal structures, especially in the dystrophin-glycoproteincomplex [22,23,39].

Interestingly, SGCE MSNs displayed significantly reduced GABAergic synaptic density in comparison to control MSNs. However, the expression of the genes encoding $\mathrm{GABA}_{\mathrm{A}}$ receptor subunits and GABAergic calcium signaling were comparable in SGCE and control MSNs. The reduced neuronal GABAergic synaptic density in striatal MSNs seen in our study could be one pathophysiological cause for the improvement of symptoms after ingestion of alcohol $[28,29,45]$ or likewise benzodiazepines $[1,42,45]$, which both enhance GABAergic transmission. Even earlier, it was suggested that the striatum plays an important pathophysiological role in DYT-SGCE but other brain regions seem to be also involved in the pathogenesis [27,33,34]. In accordance with the assumption that the striatum as part of the basal ganglia could be important for the pathogenesis of DYTSGCE, deep-brain stimulation of the internal globus pallidus and the ventral intermediate thalamic nucleus improved symptoms of DYT-SGCE patients [54-56]. A dysfunction of the cerebello-thalamico-cortical and striato-pallido-thalamo-cortical pathway, potentially due to a GABAergic deficit, is assumed to be one of the main causes of DYT-SGCE [5,23,45].

In conclusion, the differentiation of iPSCs towards striatal MSNs provides a feasible in vitro model of DYT-SGCE myoclonus-dystonia and gives insights into the functional phenotype. Despite our small number of cell lines, our data might contribute to an improved understanding of the pathophysiology of DYT-SGCE and may help to advance the development of new therapeutic strategies. However, future studies that analyze data from multiple DYT11 mutations including controls with an isogenic background are needed to determine what is the common cellular pathology.

\section{Materials and Methods}

\subsection{Cultivation of Human iPSC Lines}

Both patient-derived DYT-SGCE iPSC lines were reprogrammed using retroviruses and published recently [19] (Table 2). Genotype and phenotype of DYT-SGCE myoclonusdystonia patients were examined recently [9] indicating patient SGCE_1 (L-5007) with point mutation in SGCE c.298T>G, p.W100G and patient SGCE_2 (L-6074) with c.304C>T in SGCE, p.R102X. Both patients had brachial dystonia and myoclonus with 6 years of age at the onset of motor symptoms. No signs of psychiatric symptoms were reported [9].

The two age- and sex-matched healthy controls were also analyzed previously $[57,58]$ (Table 2). For the sake of visual clarity, we decided to illustrate figure bar graphs with pooled data of control and SGCE cell lines, respectively. Data of these healthy control lines have also been included in another manuscript [59].

During expansion, the iPSCs were cultivated feeder-free in mTeSR medium (Stemcell Technologies, Vancouver, BC, Canada) as colonies and detached using 0.5 mM EDTA for splitting every $4-7$ days [60]. 
Table 2. Characteristics of healthy control subjects and DYT-SGCE myoclonus-dystonia patients as skin fibroblast donors for iPSC lines used in this study.

\begin{tabular}{|c|c|c|c|c|}
\hline Controls & & & & \\
\hline ID code & Gender & Age at biopsy & & Previously published \\
\hline Control_1 & $\mathrm{F}$ & 48 & & Japtok et al., 2015 [57] \\
\hline Control_2 & M & 34 & & Glaß et al., 2018 [58] \\
\hline \multicolumn{5}{|c|}{ DYT-SGCE Patients } \\
\hline ID code & Gender & Age at biopsy & Genotype of locus & Previously published \\
\hline SGCE_1 & $M$ & 39 & SGCE, c.298T>G & Grütz et al., 2017 [19] \\
\hline SGCE_2 & $\mathrm{F}$ & 29 & SGCE, c. $304 C>T$ & Grütz et al., 2017 [19] \\
\hline
\end{tabular}

\subsection{Differentiation of iPSC Lines into Striatal Medium Spiny Neurons (MSNs)}

The striatal differentiation of iPSCs into medium spiny neurons (MSNs) was adapted from previous protocols published by Stanslowsky et al. [37] and Capetian et al. [38]. Briefly, feeder-free iPSC colonies were detached and suspended in mTeSR (Stemcell Technologies, Vancouver, BC, Canada) supplemented with $1 \mu \mathrm{M}$ dorsomorphin (Tocris, Bio-Techne, Minneapolis, MN, USA), $10 \mu \mathrm{M}$ SB-431542 (Tocris, Bio-Techne, Minneapolis, MN, USA), $1 \mu \mathrm{M}$ IWP2 (Merck, Darmstadt, Germany), and $10 \mu \mathrm{M}$ Rho kinase (ROCK) inhibitor Y27632 (Stemcell Technologies, Vancouver, BC, Canada) to form free-floating embryoid bodies (EBs) at day 0. On day 2, medium was replaced with 1:1 mTeSR/N2 medium (KnockoutDMEM/F-12, with 1:100 N2 supplement, Thermo Fisher Scientific, Waltham, MA, USA and $1 \%$ penicillin, streptomycin, L-glutamine, Thermo Fisher Scientific, Waltham, MA, USA) supplemented with the above-mentioned concentrations of dorsomorphin, SB-431542, and IWP2. On day 4, N2 medium was supplemented with dorsomorphin, SB-431542, IWP2, and $0.2 \mu \mathrm{M}$ purmorphamine (PMA; Enzo Life Sciences, Lörrach, Germany). On day 6 and 8, medium was replaced with N2 medium supplemented with $1 \mu \mathrm{M}$ IWP2 and $0.2 \mu \mathrm{M}$ PMA. On day 10, only N2 medium without supplements was used. On day 12, EBs were plated and kept in N2B27 maturation medium (1:1 DMEM/F-12 and Neurobasal medium containing 1:200 N2, 1:100 B27 without vitamin A, Thermo Fisher Scientific, Waltham, MA, USA) and 1\% penicillin, streptomycin, L-glutamine) with $20 \mathrm{ng} / \mathrm{mL}$ brainderived neurotrophic factor (BDNF; PeproTech, Cranbury, NJ, USA), $10 \mathrm{ng} / \mathrm{mL}$ glial cell line-derived neurotrophic factor (GDNF; PeproTech, Cranbury, NJ, USA) and $50 \mu \mathrm{M}$ dibutyryl-cAMP (dbcAMP; Sigma-Aldrich, St. Louis, MO, USA). Once the outgrowing cells reached full confluency, they were replated on laminin/poly-DL-ornithine hydrobromide (Thermo Fisher Scientific, Waltham, MA, USA) coated dishes for terminal differentiation. Maturation medium was changed every other day. Fully differentiated neuronal cells were characterized after 70 days \pm 7 days. A total of two to three independent MSN differentiations of each iPSC line (two control and two SGCE lines) were analyzed.

\subsection{Immunocytochemistry}

Immunofluorescence stainings were performed on day 16 to evaluate outgrowth of neuronal cells from plated EBs and after day $70 \pm 7$ days to quantify the amount of terminally differentiated MSNs. Cells were fixed for 20 min with $4 \%$ paraformaldehyde (PFA, Sigma-Aldrich, St. Louis, MO, USA), washed and incubated for $60 \mathrm{~min}$ with blocking solution ( $5 \%$ goat serum, $1 \%$ bovine serum albumin (BSA, Sigma-Aldrich, St. Louis, MO, USA), $0.3 \%$ Triton X-100 (Sigma-Aldrich, St. Louis, MO, USA) diluted in PBS)). The following primary antibodies were used: rabbit polyclonal anti-GABA ( $\gamma$-aminobutyric acid, 1:1000, Sigma-Aldrich, St. Louis, MO, USA), mouse anti-GABA (1:500, Abcam, Cambridge, MA, USA), rabbit polyclonal anti-TUJ1 ( $\beta$-tubulin III, 1:1000, Abcam, Cambridge, MA, USA), mouse IgG2a anti-TUJ1 (1:1000, Abcam, Cambridge, MA, USA), rabbit polyclonal antiDARPP32 (dopamine and cAMP-regulated neuronal phosphoprotein 32kDa, 1:100, Abcam, Cambridge, MA, USA), rat IgG2a anti-CTIP2 (COUP TF1-interacting protein 2, 1:300, Ab- 
cam, Cambridge, MA, USA), mouse IgG1 anti-nestin (1:300, R\&D Systems, Minnesota, MN, USA). Primary antibodies were diluted in blocking solution and incubated with the cultures overnight at $4{ }^{\circ} \mathrm{C}$. After washing, cells were incubated with the respective secondary antibodies (AlexaFluor 488 or 555, goat anti-mouse, goat anti-rabbit, goat anti-rat, 1:1000, Thermo Fisher Scientific, Waltham, MA, USA) for $2 \mathrm{~h}$ at room temperature. Mounting medium was supplemented with $0.1 \%$ DAPI (4,6-diamidino-2-phenylindole, $10 \mathrm{mg} / \mathrm{mL}$, Thermo Fisher Scientific, Waltham, MA, USA). To check for background staining, primary antibodies were omitted for one additional coverslip for each staining combination per differentiation. Specimens were visualized with a fluorescence microscope BX61 (Olympus, Shinjuku, Japan) and DP72 camera (Olympus, Shinjuku, Japan) using the analysis software $\mathrm{Cell}^{\mathrm{F}}$ (Olympus, Shinjuku, Japan). Four random visual fields per coverslip were taken from two independent differentiations for each control and SGCE line. Cells were counted manually using ImageJ (NIH, Bethesda, MD, USA). Representative images were processed using ImageJ.

\subsection{Analysis of Neuronal Morphology and Synaptic Density}

Cells were stained with primary antibodies mouse anti-TUJ1 ( $\beta$-tubulin III, 1:1000, Abcam, Cambridge, MA, USA) and rabbit anti-GABA (1:1000, Sigma-Aldrich, St. Louis, MO, USA). Pictures for image analysis were taken at 40-fold magnification using a fluorescence microscope BX61 (Olympus), DP72 camera (Olympus, Shinjuku, Japan), and software Cell ${ }^{\mathrm{F}}$ (Olympus, Shinjuku, Japan). ImageJ-based plugin NeurphologyJ [61] was used to quantify somata, neurites, attachment points, and endpoints as described previously [37,59]. Briefly, the plugin uses two different thresholds for somata and neurites, as well as the information of the approximate neurite thickness for detection and quantification of number of somata and neurites, the area of somata and neurites, and the total neurite length within an image. Those parameters were used to normalize neurites to somata to obtain a quantitative expression for total neurite outgrowth within an image. Similarly, the endpoints of a neurite were normalized to soma attachment points to receive an expression for ramification. For quantification of GABAergic synaptic density, the ImageJ plugins SynapCountJ (version 2.0) and NeuronJ (version 1.4.3) [62] were used as described previously [37,63]. In brief, NeuronJ was used to trace a neurite and this tracing was applied to SynapCount], in which GABA-positive spots along the tracing were detected within an intensity threshold. In total, 10-15 images from two independent differentiations were analyzed for each control and SGCE line.

\subsection{Calcium Imaging}

To measure intracellular calcium transients, MSNs of three to four independent differentiations (70 days \pm 7 days) per iPSC line were loaded with the membrane permeable fluorescent dye Fura 2-AM (Sigma-Aldrich, St. Louis, MO, USA). The MSNs were incubated for $20 \mathrm{~min}$ at $37^{\circ} \mathrm{C}$ with Fura 2-AM in a standard bath solution (containing $140 \mathrm{mM}$ $\mathrm{NaCl}, 5 \mathrm{mM} \mathrm{KCl}, 2 \mathrm{mM} \mathrm{CaCl} 2,10 \mathrm{mM}$ glucose, and $10 \mathrm{mM}$ HEPES, adjusted to $\mathrm{pH} 7.4$ with $\mathrm{NaOH}$ ). To image intracellular calcium, Fura 2-AM loaded MSNs were excited at wavelengths of $340 / 380 \mathrm{~nm}$ and monitored every $300 \mathrm{~ms}$. Recordings were performed on an upright microscope Axioskop 2 FS plus (Carl Zeiss MicroImaging GmbH, Göttingen, Germany) connected to a Till Vision Imaging System (TILL Photonics, Gräfelfing, Germany). Emitted fluorescence was collected by a charge-coupled device (CCD) camera as described previously $[59,64]$. To monitor spontaneous intracellular $\mathrm{Ca}^{2+}$ changes, MSNs with a preferably multipolar dendritic morphology were imaged for $6 \mathrm{~min}$. Further, the neurotransmitters glycine $(100 \mu \mathrm{M})$, GABA $(100 \mu \mathrm{M})$, acetylcholine $(100 \mu \mathrm{M})$, and glutamate $(50 \mu \mathrm{M})$ were applied to MSNs after $1 \mathrm{~min}$ baseline condition and the provoked intracellular $\mathrm{Ca}^{2+}$ changes were recorded for $1 \mathrm{~min}$ followed by perfusion with bath solution. Note, glycine- and GABA-induced $\mathrm{Ca}^{2+}$ peaks suggest a slight depolarizing effect of these neurotransmitters in some cells, most likely due to a high intracellular chloride concentration $[65,66]$. Recordings were terminated by application of $\mathrm{KCl}(50 \mathrm{mM})$ to induce 
neuronal depolarization and ensure the viability and excitability of the recorded cells. After background subtraction, the 340/380 nm excitation ratio for Fura 2-AM was calculated which increases as a function of the cytosolic free $\mathrm{Ca}^{2+}$ concentration $\left(\left[\mathrm{Ca}^{2+}\right]_{\mathrm{i}}\right)$. For analysis of spontaneous $\mathrm{Ca}^{2+}$ transients, only $\mathrm{Ca}^{2+}$ signals with a $340 / 380 \mathrm{~nm}$ excitation ratio of Fura 2-AM of $\geq 0.02$ of individual MSNs were used. For analysis of response amplitudes after neurotransmitter application, only $\mathrm{Ca}^{2+}$ signals with a $340 / 380 \mathrm{~nm}$ excitation ratio of Fura 2-AM $\geq 0.05$ of individual MSNs were used [59]. Additional experiments in Fura-2 loaded MSNs were performed in which verapamil $(100 \mu \mathrm{M}$, Sigma-Aldrich, St. Louis, $\mathrm{MO}$, USA, to block voltage-gated calcium channels), diluted in a bath solution with $\mathrm{KCl}$ (50 mM), was applied to MSNs after $1 \mathrm{~min}$ baseline condition. Furthermore, experiments with separate application of either atropine $(10 \mu \mathrm{M}$, Sigma-Aldrich, St. Louis, MO, USA, muscarinic acetylcholine receptor antagonist) or mecamylamine ( $20 \mu \mathrm{M}$, Sigma-Aldrich, St. Louis, MO, USA, nicotinic acetylcholine receptor antagonist) diluted in a bath solution with acetylcholine $(100 \mu \mathrm{M})$ to Fura-2 loaded MSNs were recorded. The calcium peaks of each individual experiment were used to calculate the percentage of blocking for each antagonist. Per independent differentiation, at least two coverslips with 10-40 MSNs from two control lines and two SGCE lines were investigated.

\subsection{Quantitative Real-Time PCR}

For RNA extraction, iPSCs and differentiated MSNs (collected at day 70 days \pm 7 days) were processed using RNeasy Mini Kit (Qiagen, Venlo, The Netherlands) including a column DNase digestion. The quality of total RNA was checked by Nanodrop analysis (Nanodrop Technologies, Wilmington, DE, USA). A total of $250 \mathrm{ng}$ of RNA was transcribed into cDNA using QuantiTect reverse transcription kit (Qiagen). Quantitative real-time PCR reaction analysis was performed [61] using Power SYBR PCR Green Master Mix (Thermo Fisher Scientific, Waltham, MA, USA) in a StepOnePlus cycler (Thermo Fisher Scientific, Waltham, MA, USA) under following conditions: $95^{\circ} \mathrm{C}$ for $10 \mathrm{~min}$ followed by 40 cycles of $95^{\circ} \mathrm{C}$ for $15 \mathrm{~s}$ and $60^{\circ} \mathrm{C}$ for $1 \mathrm{~min}$. Per reaction, a total amount of $1.75 \mathrm{ng}$ RNA transcribed to cDNA was analyzed and $1.75 \mu \mathrm{M}$ of forward and reverse primers were used. As recommended by the MIQE-guidelines [67], specificity of PCR products was ensured by melting curve analysis and equal PCR efficiency of all primer pairs was validated by serial dilutions of cDNA. For the following primer pairs and PCR products, the PCR efficiency or detection limit $\mathrm{Ct}<30$ were not meeting the quality criteria by the MIQE guidelines and were not included in further analysis: primer pairs for target genes CHRNA1, CHRNA2, CHRNB1, CHRNB3 encoding respective nicotinic acetylcholine receptor (nAChR) subunits. The threshold cycle $(\mathrm{Ct})$ values of target genes were normalized to expression of endogenous references beta2-microglobulin (B2M), glyceraldehyde 3-phosphate dehydrogenase (GAPDH) and $\beta$-actin with the following formula: [Ct (target) - $\mathrm{Ct}$ (reference) $=\Delta \mathrm{Ct}]$. Gene expression of three independent differentiations per cell line (two control lines and two SGCE lines), each in triplicate, were used for analysis and illustrated as means \pm standard error of the mean (SEM). For a list of all primer sequences of $G_{A B A}$ receptor [66], voltage-gated calcium channel, nicotinic and muscarinic acetylcholine receptor subunits see Supplementary Tables S1-S4.

\subsection{Electrophysiology}

Electrophysiological patch-clamp measurements of MSNs were performed after 70 days \pm 7 days of differentiation in vitro from at least three to four independent differentiations per iPSC line as described previously $[37,59,64]$. To identify MSNs, only mediumsized multipolar neurons were used for analyses. This morphological selection approach had previously yielded $>90 \%$ of DARPP-32 positive MSNs in whole-cell recordings [38]. Patch-clamp pipettes with final resistances of 3-4 $\mathrm{M} \Omega$ were filled with an internal solution (153 mM KCl, $1 \mathrm{mM} \mathrm{MgCl} 2,10 \mathrm{mM}$ HEPES, and $5 \mathrm{mM}$ EGTA, adjusted to $\mathrm{pH} 7.3$ with $\mathrm{KOH}, 305 \mathrm{mOsm}$ ). The external bath solution contained $142 \mathrm{mM} \mathrm{NaCl}, 8 \mathrm{mM} \mathrm{KCl}$, $1 \mathrm{mM} \mathrm{CaCl}_{2}, 6 \mathrm{mM} \mathrm{MgCl}_{2}, 10 \mathrm{mM}$ glucose, and $10 \mathrm{mM}$ HEPES, adjusted to $\mathrm{pH} 7.4$ with 
$\mathrm{NaOH}, 325 \mathrm{mOsm}$ ). Whole-cell currents were low-pass filtered at $2.9 \mathrm{kHz}$, digitized at $10 \mathrm{kHz}$ using an EPC-10 amplifier (HEKA Elektronik, Harvard Bioscience, MA USA), and analyzed with PatchMaster and FitMaster software (HEKA). Sodium and potassium ion currents were elicited by depolarizing voltage steps in increments of $10 \mathrm{mV}$ from a holding potential of -70 to $40 \mathrm{mV}$. Miniature postsynaptic currents (mPSCs), indicating mostly GABAergic synaptic activity in MSNs [37,38], were acquired at a holding potential of $-70 \mathrm{mV}$ in voltage-clamp mode. For quantitative analysis only mPSCs amplitudes between 10-100 pA were measured to exclude noise artefacts $(<10 \mathrm{pA})$ and action potential activity $(>100 \mathrm{pA})$ of the recorded neuron. Spontaneous and evoked action potentials (APs) were recorded in current-clamp mode at holding potentials of -50 to $-70 \mathrm{mV}$. For recordings, MSNs from at least two independent differentiations from two control lines and two SGCE lines were investigated.

\subsection{Statistical Analyses}

Statistical analysis was performed using GraphPad Prism 5 Software (GraphPad Software, San Diego, CA, USA). All data of MSNs from healthy controls and SGCE lines were pooled in control and SGCE groups for the respective experiments and are presented as mean \pm standard error of the mean (SEM). When the two groups showed normal distribution, a two-tailed unpaired t-test, in other cases a nonparametric Mann-Whitney-U test was calculated comparing the two groups (control versus SGCE). Two-way ANOVA followed by Bonferroni post hoc analysis was used for multiple comparisons, when comparing more than two groups. The significance level ( $p$-value) was set to $p<0.05$ with $* p<0.05$, ${ }^{* *} p<0.01,{ }^{* * *} p<0.001$.

Supplementary Materials: The following are available online at https://www.mdpi.com/article/ 10.3390/ijms22073565/s1, Table S1: Quantitative real-time PCR analysis of selected and reference genes for iPSCs and MSNs after 70 days of differentiation in vitro, Table S2: Quantitative real-time PCR analysis of voltage-gated $\mathrm{Ca}^{2+}$-channel subunit expression in MSNs after 70 days differentiation in vitro. Table S3: Quantitative real-time PCR analysis of $\mathrm{GABA}_{\mathrm{A}}$ receptor subunit expression in MSNs after 70 days of differentiation in vitro. Table S4: Quantitative real-time PCR analysis of nicotinic and muscarinic acetylcholine receptor subunit expression in MSNs after 70 days differentiation in vitro.

Author Contributions: Conceptualization, A.K., F.W. and S.S.; methodology, A.K., S.S., F.W.; formal analysis, A.K. and S.S.; investigation, A.K., S.S., F.W., N.K., T.G., L.M.H. and J.H.; visualization, S.S., A.K.; writing —original draft preparation, A.K., S.S. and F.W.; writing-review and editing, K.G., A.G., H.G., J.H., N.K., P.S., A.H. and F.W.; supervision, F.W. All authors have read and agreed to the published version of the manuscript.

Funding: This research was funded by the Karlheinz-Hartmann-Stiftung (Hannover, Germany) to F.W. and the Ellen-Schmidt-Program (Hannover, Germany) to A.K., K.G. received intramural funding from the University of Lübeck. A.H. is supported by the Hermann and Lilly Schilling Stiftung für medizinische Forschung im Stifterverband. P.S. was supported by the German Research Foundation (FOR2488).

Institutional Review Board Statement: Not applicable.

Informed Consent Statement: Not applicable.

Data Availability Statement: Data is contained within the article or supplementary material.

Acknowledgments: The authors wish to thank Andreas Niesel, Niko Hensel and Tobias Schüning for their excellent technical support.

Conflicts of Interest: The authors declare no conflict of interest. 


\section{References}

1. Kinugawa, K.; Vidailhet, M.; Clot, F.; Apartis, E.; Grabli, D.; Roze, E. Myoclonus-dystonia: An update. Mov. Disord. 2009, 24, 479-489. [CrossRef] [PubMed]

2. Albanese, A.; Bhatia, K.; Bressman, S.B.; DeLong, M.R.; Fahn, S.; Fung, V.S.; Hallett, M.; Jankovic, J.; Jinnah, H.A.; Klein, C.; et al. Phenomenology and classification of dystonia: A consensus update. Mov. Disord. 2013, 28, 863-873. [CrossRef] [PubMed]

3. Peall, K.J.; Kurian, M.A.; Wardle, M.; Waite, A.J.; Hedderly, T.; Lin, J.-P.; Smith, M.; Whone, A.L.; Pall, H.; White, C.; et al. SGCE and myoclonus dystonia: Motor characteristics, diagnostic criteria and clinical predictors of genotype. J. Neurol. 2014, 261, 2296-2304. [CrossRef] [PubMed]

4. Marras, C.; Lang, A.; Van De Warrenburg, B.P.; Sue, C.M.; Tabrizi, S.J.; Bertram, L.; Mercimek-Mahmutoglu, S.; Ebrahimi-Fakhari, D.; Warner, T.T.; Durr, A.; et al. Nomenclature of genetic movement disorders: Recommendations of the international Parkinson and movement disorder society task force. Mov. Disord. 2016, 31, 436-457. [CrossRef]

5. Roze, E.; Lang, A.E.; Vidailhet, M. Myoclonus-dystonia: Classification, phenomenology, pathogenesis, and treatment. Curr. Opin. Neurol. 2018, 31, 484-490. [CrossRef]

6. Asmus, F.; Zimprich, A.; Du Montcel, S.T.; Kabus, C.; Deuschl, G.; Kupsch, A.; Ziemann, U.; Castro, M.; Kühn, A.A.; Strom, T.M.; et al. Myoclonus-dystonia syndrome: $\varepsilon$-sarcoglycan mutations and phenotype. Ann. Neurol. 2002, 52, 489-492. [CrossRef]

7. Saunders-Pullman, R.; Shriberg, J.; Heiman, G.; Raymond, D.; Wendt, K.; Kramer, P.; Schilling, K.; Kurlan, R.; Klein, C.; Ozelius, L.J.; et al. Myoclonus dystonia: Possible association with obsessive-compulsive disorder and alcohol dependence. Neurology 2002, 58, 242-245. [CrossRef]

8. Hess, C.W.; Raymond, D.; Aguiar, P.D.C.; Frucht, S.; Shriberg, J.; Heiman, G.A.; Kurlan, R.; Klein, C.; Bressman, S.B.; Ozelius, L.J.; et al. Myoclonus-dystonia, obsessive-compulsive disorder, and alcohol dependence in SGCE mutation carriers. Neurology 2007, 68, 522-524. [CrossRef]

9. Weissbach, A.; Kasten, M.; Grünewald, A.; Brüggemann, N.; Trillenberg, P.; Klein, C.; Hagenah, J. Prominent psychiatric comorbidity in the dominantly inherited movement disorder myoclonus-dystonia. Park. Relat. Disord. 2013, 19, $422-425$. [CrossRef]

10. Peall, K.J.; Dijk, J.M.; Saunders-Pullman, R.; Dreissen, Y.E.M.; Van Loon, I.; Cath, D.C.; Kurian, M.A.; Owen, M.J.; Foncke, E.M.J.; Morris, H.R.; et al. Psychiatric disorders, myoclonus dystonia and SGCE: An international study. Ann. Clin. Transl. Neurol. 2016, 3, 4-11. [CrossRef]

11. Cif, L.; Valente, E.M.; Hemm, S.; Coubes, C.; Vayssiere, N.; Serrat, S.; Di Giorgio, A.; Coubes, P. Deep brain stimulation in myoclonus-dystonia syndrome. Mov. Disord. 2004, 19, 724-727. [CrossRef]

12. Kurtis, M.M.; Luciano, M.S.; Yu, Q.; Goodman, R.R.; Ford, B.; Raymond, D.; Pullman, S.L.; Saunders-Pullman, R. Clinical and neurophysiological improvement of SGCE myoclonus-dystonia with GPi deep brain stimulation. Clin. Neurol. Neurosurg. 2010, 112, 149-152. [CrossRef]

13. Thenganatt, M.A.; Jankovic, J. Treatment of Dystonia. Neurotherapeutics 2013, 11, 139-152. [CrossRef]

14. Zimprich, A.; Grabowski, M.; Asmus, F.; Naumann, M.; Berg, D.; Bertram, M.; Scheidtmann, K.H.; Kern, P.; Winkelmann, J.; Müller-Myhsok, B.; et al. Mutations in the gene encoding $\epsilon$-sarcoglycan cause myoclonus-dystonia syndrome. Nat. Genet. 2001, 29, 66-69. [CrossRef]

15. Asmus, F.; Salih, F.; Hjermind, L.E.; Ostergaard, K.; Munz, M.; Kühn, A.A.; Dupont, E.; Kupsch, A.; Gasser, T. Myoclonus-dystonia due to genomic deletions in the epsilon-sarcoglycan gene. Ann. Neurol. 2005, 58, 792-797. [CrossRef]

16. Grünewald, A.; Djarmati, A.; Lohmann-Hedrich, K.; Farrell, K.; Zeller, J.A.; Allert, N.; Papengut, F.; Petersen, B.; Fung, V.; Sue, C.M.; et al. Myoclonus-dystonia: Significance of large SGCE deletions. Hum. Mutat. 2008, 29, 331-332. [CrossRef]

17. Grabowski, M.; Zimprich, A.; Lorenz-Depiereux, B.; Kalscheuer, V.; Asmus, F.; Gasser, T.; Meitinger, T.; Strom, T.M. The epsilonsarcoglycan gene (SGCE), mutated in myoclonus-dystonia syndrome, is maternally imprinted. Eur. J. Hum. Genet. 2003, 11, 138-144. [CrossRef]

18. Müller, B.; Hedrich, K.; Kock, N.; Dragasevic, N.; Svetel, M.; Garrels, J.; Landt, O.; Nitschke, M.; Pramstaller, P.P.; Reik, W.; et al. Evidence That Paternal Expression of the $\varepsilon$-Sarcoglycan Gene Accounts for Reduced Penetrance in Myoclonus-Dystonia. Am. J. Hum. Genet. 2002, 71, 1303-1311. [CrossRef]

19. Grütz, K.; Seibler, P.; Weissbach, A.; Lohmann, K.; Carlisle, F.A.; Blake, D.J.; Westenberger, A.; Klein, C.; Grünewald, A. Faithful SGCE imprinting in iPSC-derived cortical neurons: An endogenous cellular model of myoclonus-dystonia. Sci. Rep. 2017, 7, srep41156. [CrossRef]

20. Ozawa, E.; Mizuno, Y.; Hagiwara, Y.; Sasaoka, T.; Yoshida, M. Molecular and cell biology of the sarcoglycan complex. Muscle Nerve 2005, 32, 563-576. [CrossRef]

21. Ritz, K.; van Schaik, B.D.; Jakobs, M.E.; van Kampen, A.H.; Aronica, E.; Tijssen, M.A.; Baas, F. SGCE isoform characterization and expression in human brain: Implications for myoclonus-dystonia pathogenesis? Eur. J. Hum. Genet. 2011, 19, 438-444. [CrossRef] [PubMed]

22. Waite, A.J.; Carlisle, F.A.; Chan, Y.M.; Blake, D.J. Myoclonus dystonia and muscular dystrophy: $\epsilon$-sarcoglycan is part of the dystrophin-associated protein complex in brain. Mov. Disord. 2016, 31, 1694-1703. [CrossRef] [PubMed]

23. Menozzi, E.; Balint, B.; Latorre, A.; Valente, E.M.; Rothwell, J.C.; Bhatia, K.P. Twenty years on: Myoclonus-dystonia and $\varepsilon$-sarcoglycan-Neurodevelopment, channel, and signaling dysfunction. Mov. Disord. 2019, 34, 1588-1601. [CrossRef] [PubMed] 
24. Dragicevic, E.; Poetschke, C.; Duda, J.; Schlaudraff, F.; Lammel, S.; Schiemann, J.; Fauler, M.; Hetzel, A.; Watanabe, M.; Lujan, R.; et al. $\mathrm{Ca}_{\mathrm{v}} 1.3$ channels control D2-autoreceptor responses via NCS-1 in substantia nigra dopamine neurons. Brain 2014, 137, 2287-2302. [CrossRef]

25. Beukers, R.J.; Booij, J.; Weisscher, N.; Zijlstra, F.S.M.; Van Amelsvoort, T.A.M.J.; Tijssen, M.A.J. Reduced striatal D2 receptor binding in myoclonus-dystonia. Eur. J. Nucl. Med. Mol. Imaging 2008, 36, 269-274. [CrossRef]

26. Zhang, L.; Yokoi, F.; Parsons, D.S.; Standaert, D.G.; Li, Y. Alteration of Striatal Dopaminergic Neurotransmission in a Mouse Model of DYT11 Myoclonus-Dystonia. PLoS ONE 2012, 7, e33669. [CrossRef]

27. Yokoi, F.; Dang, M.T.; Li, J.; Li, Y. Myoclonus, Motor Deficits, Alterations in Emotional Responses and Monoamine Metabolism in $\varepsilon$-Sarcoglycan Deficient Mice. J. Biochem. 2006, 140, 141-146. [CrossRef]

28. Gasser, T. Inherited myoclonus-dystonia syndrome. Adv. Neurol. 1998, 78, 325-334.

29. Weissbach, A.; Werner, E.; Bally, J.F.; Tunc, S.; Löns, S.; Timmann, D.; Zeuner, K.E.; Tadic, V.; Brüggemann, N.; Lang, A.; et al. Alcohol improves cerebellar learning deficit in myoclonus-dystonia: A clinical and electrophysiological investigation. Ann. Neurol. 2017, 82, 543-553. [CrossRef]

30. Knuesel, I.; Mastrocola, M.; Zuellig, R.A.; Bornhauser, B.; Schaub, M.C.; Fritschy, J.-M. Altered synaptic clustering of GABA A receptors in mice lacking dystrophin (mdx mice). Eur. J. Neurosci. 1999, 11, 4457-4462. [CrossRef]

31. Kueh, S.L.L.; Head, S.I.; Morley, J.W. GABA ${ }_{\mathrm{A}}$ Receptor Expression and Inhibitory Post-Synaptic Currents in Cerebellar Purkinje Cells in Dystrophin-Deficient $m d x$ Mice. Clin. Exp. Pharmacol. Physiol. 2007, 35, 207-210. [CrossRef]

32. Waite, A.; Brown, S.C.; Blake, D.J. The dystrophin-glycoprotein complex in brain development and disease. Trends Neurosci. 2012, 35, 487-496. [CrossRef]

33. Maltese, M.; Martella, G.; Imbriani, P.; Schuermans, J.; Billion, K.; Sciamanna, G.; Farook, F.; Ponterio, G.; Tassone, A.; Santoro, M.; et al. Abnormal striatal plasticity in a DYT11/SGCE myoclonus dystonia mouse model is reversed by adenosine A2A receptor inhibition. Neurobiol. Dis. 2017, 108, 128-139. [CrossRef]

34. Yokoi, F.; Dang, M.T.; Zhou, T.; Li, Y. Abnormal nuclear envelopes in the striatum and motor deficits in DYT11 myoclonus-dystonia mouse models. Hum. Mol. Genet. 2011, 21, 916-925. [CrossRef]

35. Washburn, S.; Fremont, R.; Moreno-Escobar, M.C.; Angueyra, C.; Khodakhah, K. Acute cerebellar knockdown of Sgce reproduces salient features of myoclonus-dystonia (DYT11) in mice. eLife 2019, 8. [CrossRef]

36. Van Der Meer, J.N.; Beukers, R.J.; Van Der Salm, S.M.A.; Caan, M.W.A.; Tijssen, M.A.J.; Nederveen, A.J. White matter abnormalities in gene-positive myoclonus-dystonia. Mov. Disord. 2012, 27, 1666-1672. [CrossRef]

37. Stanslowsky, N.; Reinhardt, P.; Glass, H.; Kalmbach, N.; Naujock, M.; Hensel, N.; Lübben, V.; Pal, A.; Venneri, A.; Lupo, F.; et al. Neuronal Dysfunction in iPSC-Derived Medium Spiny Neurons from Chorea-Acanthocytosis Patients Is Reversed by Src Kinase Inhibition and F-Actin Stabilization. J. Neurosci. 2016, 36, 12027-12043. [CrossRef]

38. Capetian, P.; Stanslowsky, N.; Bernhardi, E.; Grütz, K.; Domingo, A.; Brüggemann, N.; Naujock, M.; Seibler, P.; Klein, C.; Wegner, F. Altered glutamate response and calcium dynamics in iPSC-derived striatal neurons from XDP patients. Exp. Neurol. 2018, 308, 47-58. [CrossRef]

39. Haws, C.M.; Lansman, J.B. Calcium-permeable ion channels in cerebellar neurons from mdx mice. Proc. R. Soc. B Boil. Sci. 1991, 244, 185-189. [CrossRef]

40. Hicks, C.B.; Abraham, K. Verapamil and Myoclonic Dystonia. Ann. Intern. Med. 1985, 103, 154. [CrossRef]

41. Vadlamudi, L.; Wijdicks, E.F. Multifocal myoclonus due to verapamil overdose. Neurology 2002, 58, 984. [CrossRef]

42. Goetz, C.G.; Horn, S.S. Treatment of tremor and dystonia. Neurol. Clin. 2001, 19, 129-144. [CrossRef]

43. Raymond, D.; Saunders-Pullman, R.; Ozelius, L.A. SGCE Myoclonus-Dystonia. In GeneReviews@; Adam, M.P., Ardinger, H.H., Pagon, R.A., Eds.; University of Washington: Seattle, WA, USA, 2003.

44. Jaunarajs, K.E.; Bonsi, P.; Chesselet, M.; Standaert, D.; Pisani, A. Striatal cholinergic dysfunction as a unifying theme in the pathophysiology of dystonia. Prog. Neurobiol. 2015, 127-128, 91-107. [CrossRef]

45. Fearon, C.; Peall, K.J.; Vidailhet, M.; Fasano, A. Medical management of myoclonus-dystonia and implications for underlying pathophysiology. Park. Relat. Disord. 2020, 77, 48-56. [CrossRef]

46. Maltese, M.; Martella, G.; Madeo, G.; Fagiolo, I.; Tassone, A.; Ponterio, G.; Sciamanna, G.; Burbaud, P.; Conn, P.J.; Bonsi, P.; et al. Anticholinergic drugs rescue synaptic plasticity in DYT1 dystonia: Role of $\mathrm{M}_{1}$ muscarinic receptors. Mov. Disord. 2014, 29, 1655-1665. [CrossRef]

47. Erosa-Rivero, H.B.; Bata-García, J.L.; Alvarez-Cervera, F.J.; Heredia-López, F.J.; Góngora-Alfaro, J.L. The potency and efficacy of anticholinergics to inhibit haloperidol-induced catalepsy in rats correlates with their rank order of affinities for the muscarinic receptor subtypes. Neuropharmacology 2014, 81, 176-187. [CrossRef]

48. Hamann, M.; Plank, J.; Richter, F.; Bode, C.; Smiljanic, S.; Creed, M.; Nobrega, J.N.; Richter, A. Alterations of M1 and M4 acetylcholine receptors in the genetically dystonic $\left(d t^{s z}\right)$ hamster and moderate antidystonic efficacy of M1 and M4 anticholinergics. Neuroscience 2017, 357, 84-98. [CrossRef] [PubMed]

49. Hersch, S.M.; Gutekunst, C.A.; Rees, H.D.; Heilman, C.J.; Levey, A.I. Distribution of m1-m4 muscarinic receptor proteins in the rat striatum: Light and electron microscopic immunocytochemistry using subtype- specific antibodies. J. Neurosci. 1994, 14, 3351-3363. [CrossRef] [PubMed]

50. Chatzidaki, A.; Fouillet, A.; Li, J.; Dage, J.; Millar, N.S.; Sher, E.; Ursu, D. Pharmacological Characterisation of Nicotinic Acetylcholine Receptors Expressed in Human iPSC-Derived Neurons. PLoS ONE 2015, 10, e0125116. [CrossRef] [PubMed] 
51. Zoli, M.; Moretti, M.; Zanardi, A.; McIntosh, J.M.; Clementi, F.; Gotti, C. Identification of the Nicotinic Receptor Subtypes Expressed on Dopaminergic Terminals in the Rat Striatum. J. Neurosci. 2002, 22, 8785-8789. [CrossRef] [PubMed]

52. Ghedini, P.C.; Avellar, M.C.W.; De Lima, T.C.M.; Lima-Landman, M.T.R.; Lapa, A.J.; Souccar, C. Quantitative changes of nicotinic receptors in the hippocampus of dystrophin-deficient mice. Brain Res. 2012, 1483, 96-104. [CrossRef]

53. Parames, S.; Coletta-Yudice, E.; Nogueira, F.; De Sousa, M.N.; Hayashi, M.; Lima-Landman, M.; Lapa, A.; Souccar, C. Altered acetylcholine release in the hippocampus of dystrophin-deficient mice. Neuroscience 2014, 269, 173-183. [CrossRef]

54. Gruber, D.; Kühn, A.A.; Schoenecker, T.; Kivi, A.; Trottenberg, T.; Hoffmann, K.-T.; Gharabaghi, A.; Kopp, U.A.; Schneider, G.-H.; Klein, C.; et al. Pallidal and thalamic deep brain stimulation in myoclonus-dystonia. Mov. Disord. 2010, 25, 1733-1743. [CrossRef]

55. Wang, J.-W.; Li, J.-P.; Wang, Y.-P.; Zhang, X.-H.; Zhang, Y.-Q. Deep brain stimulation for myoclonus-dystonia syndrome with double mutations in DYT1 and DYT11. Sci. Rep. 2017, 7, 1-6. [CrossRef]

56. Krause, P.; Koch, K.; Gruber, D.; Kupsch, A.; Gharabaghi, A.; Schneider, G.; Kühn, A.A. Long-term effects of pallidal and thalamic deep brain stimulation in myoclonus dystonia. Eur. J. Neurol. 2021. [CrossRef]

57. Japtok, J.; Lojewski, X.; Naumann, M.; Klingenstein, M.; Reinhardt, P.; Sterneckert, J.; Putz, S.; Demestre, M.; Boeckers, T.M.; Ludolph, A.C.; et al. Stepwise acquirement of hallmark neuropathology in FUS-ALS iPSC models depends on mutation type and neuronal aging. Neurobiol. Dis. 2015, 82, 420-429. [CrossRef]

58. Glaß, H.; Pal, A.; Reinhardt, P.; Sterneckert, J.; Wegner, F.; Storch, A.; Hermann, A. Defective mitochondrial and lysosomal trafficking in chorea-acanthocytosis is independent of Src-kinase signaling. Mol. Cell. Neurosci. 2018, 92, 137-148. [CrossRef]

59. Staege, S.; Kutschenko, A.; Baumann, H.; Glaß, H.; Henkel, L.; Gschwendtberger, T.; Kalmbach, N.; Klietz, M.; Hermann, A.; Lohmann, K.; et al. Reduced expression of GABA(A) receptor alpha2 subunit is associated with disinhibition of DYT-THAP1 dystonia patient-derived striatal medium spiny neurons. Front. Cell. Dev. Biol. 2021. under review.

60. WiCell. Feeder-independent culture protocol-EDTA splitting. In StemBook; Harvard Stem Cell Institute: Cambridge, MA, USA, 2014. [CrossRef]

61. Ho, S.-Y.; Chao, C.-Y.; Huang, H.-L.; Chiu, T.-W.; Charoenkwan, P.; Hwang, E. NeurphologyJ: An automatic neuronal morphology quantification method and its application in pharmacological discovery. BMC Bioinform. 2011, 12, 1-18. [CrossRef]

62. Meijering, E.; Jacob, M.; Sarria, J.-C.; Steiner, P.; Hirling, H.; Unser, M. Design and validation of a tool for neurite tracing and analysis in fluorescence microscopy images. Cytomatics 2004, 58, 167-176. [CrossRef]

63. Hensel, N.; Schön, A.; Konen, T.; Lübben, V.; Förthmann, B.; Baron, O.; Grothe, C.; Leifheit-Nestler, M.; Claus, P.; Haffner, D. Fibroblast growth factor 23 signaling in hippocampal cells: Impact on neuronal morphology and synaptic density. J. Neurochem. 2016, 137, 756-769. [CrossRef]

64. Stanslowsky, N.; Haase, A.; Martin, U.; Naujock, M.; Leffler, A.; Dengler, R.; Wegner, F. Functional differentiation of midbrain neurons from human cord blood-derived induced pluripotent stem cells. Stem Cell Res. Ther. 2014, 5, 1-14. [CrossRef]

65. Wegner, F.; Kraft, R.; Busse, K.; Härtig, W.; Ahrens, J.; Leffler, A.; Dengler, R.; Schwarz, J. Differentiated Human Midbrain-Derived Neural Progenitor Cells Express Excitatory Strychnine-Sensitive Glycine Receptors Containing $\alpha 2 \beta$ Subunits. PLoS ONE 2012, 7, e36946. [CrossRef]

66. Wegner, F.; Kraft, R.; Busse, K.; Härtig, W.; Schaarschmidt, G.; Schwarz, S.C.; Schwarz, J.; Hevers, W. Functional and molecular analysis of $\mathrm{GABA}_{\mathrm{A}}$ receptors in human midbrain-derived neural progenitor cells. J. Neurochem. 2008, 107, 1056-1069. [CrossRef]

67. Bustin, S.A.; Benes, V.; Garson, J.A.; Hellemans, J.; Huggett, J.; Kubista, M.; Mueller, R.; Nolan, T.; Pfaffl, M.W.; Shipley, G.L.; et al. The MIQE Guidelines: Minimum Information for Publication of Quantitative Real-Time PCR Experiments. Clin. Chem. 2009, 55, 611-622. [CrossRef] 